\title{
Endogenous Technical Change in a Competitive Economy
}

\author{
Martin Hellwig and Andreas Irmen* \\ University of Mannheim \\ Department of Economics \\ D-68131 Mannheim \\ hellwig@pool.uni-mannheim.de/airmen@pool.uni-mannheim.de
}

\section{March 1999}

\begin{abstract}
We develop a model of endogenous growth in an economy with competitive markets. Technical change arises from the intentional actions of entrepreneurs looking for profits. Opportunities for such profits stem from inframarginal rents. This provides a counterexample to the widespread view that endogenous technical change is possible only if innovating firms can expect to reap monopoly or oligopoly rents. The model has a unique equilibrium, which involves steady growth at a positive rate. Equilibrium growth is inefficiently low because knowledge spillover effects are neglected. The inefficiency can be eliminated by an interest rate subsidy.
\end{abstract}

Keywords: endogenous technical change, perfect competition, productivity growth, wages, employment

JEL Classification: O4, E24, J30, D24, D41, D92

*Financial assistance from Deutsche Forschungsgemeinschaft under the program "Industrieökonomik und Inputmärkte" is gratefully acknowledged. 


\section{Introduction}

In this paper we develop a model of endogenous growth in an economy with competitive markets. Technical change arises from the intentional actions of entrepreneurs looking for profits. Opportunities for such profits are available even though there are no monopoly rents. This provides a counterexample to the widespread view that endogenous technical change is possible only if innovating firms can expect to reap monopoly or oligopoly rents. This view goes back to Schumpeter (1911/1934); in the recent literature it has been expressed, e.g., by Romer (1990), Grossman and Helpman (1991), Peretto (1996), and Aghion and Howitt (1998). In a typical formulation, Peretto (1996, p. 897) asserts that imperfect markets and monopoly power are necessary to induce profit-seeking agents to undertake costly R\&D.

We do not want to dispute the notion that prospects of monopoly rents encourage innovative activities. We merely want to argue that profit opportunities in competitive markets may also provide incentives for innovative activities. If production technologies are strictly convex, there will be inframarginal rents providing for an excess of revenues over variable production costs even when firms take prices as given. Such inframarginal rents may provide compensation for the costs of research and development; spending on research and development may be desirable as a way to increase such rents. ${ }^{1}$

Strictly convex technologies and inframarginal rents have largely been excluded from growth theory because they seem incompatible with the standard assumption of constant returns to scale. Tradition, or perhaps a concern for the stylized facts of economic growth (Kaldor (1961), Solow (1970)) and the steady-state growth patterns that these stylized facts suggest, have led the profession to focus on growth models with constant returns to scale in production. Given this specification, Euler's law ensures that for a price-taking firm, revenues are equal to variable production costs, there are no inframarginal rents, and hence there is no compensation for research and development (see, e.g., Romer (1990)).

In this line of argument, the assumption of constant returns to scale appears in two distinct guises: At one level, constant returns to scale are seen as a condition on aggregate technology, taken to be implied by observed evolutions of interest rates, capital intensity, etc. at the level of the overall economy. At another level, constant returns to scale concern the individual firm as this firm chooses

\footnotetext{
${ }^{1}$ The idea that a competitive environment may leave room for financing of expenditure on research and development already appears in a partial equilibrium model of Shell (1973). He considers two types of price taking firms. A large but finite set of firms employs an advanced technology, the others operate at an old technology. Rents appear in the form of quasi-rents on advanced technology and arise if industry output exceeds the quantity produced by the set of advanced firms at minimum unit costs.
} 
profit-maximizing production plans and finds that maximum profits (before consideration of R\&D spending) at equilibrium prices are zero. Our analysis is based on the observation that there is no necessary link between constant returns to scale at the level of aggregates and constant returns to scale at the level of the individual firm. This observation has previously been made by Bester and Petrakis (1998); we follow their specification and embed it in a general-equilibrium model of aggregate economic growth.

Regardless of what technologies are at the level of the individual firm, at the level of economy-wide aggregates, constant returns are guaranteed if one assumes that technologies of individual firms can be replicated ad libitum. We assume that the economy contains a large ocean of small (atomless) firms, each of which has access to the same technology. This assumption guarantees that if a production plan is feasible at the level of the individual firm, then an arbitrary nonnegative multiple of this plan is feasible at the level of the economy. This is enough to allow the kind of steady-state growth patterns that are suggested by the stylized facts of economic growth.

At the level of individual firms, we specify technologies in such a way that for a given production technique, the set of feasible input-output combinations is strictly convex. In addition there is a possibility of improving production techniques through prior resource spending; this introduces a nonconvexity because the R\&D spending is not related to subsequent output and corresponds to a fixed cost. The combination of strict convexity of the technology for a given production technique and the nonconvexity from research and development makes it possible to have both, marginal-cost pricing of output and free entry into R\&D cum production, i.e., zero profits net of R\&D spending.

The specification we use has production of a firm at any time depend on its labor and capital inputs and on the resources it has devoted to improving labor productivity. Labor inputs are provided in the period of production, capital inputs and productivity improvement resources are provided one period before. Labor and capital are strict complements; capital has decreasing returns even when it is the limiting factor. This is the source of inframarginal rents.

Bester and Petrakis (1998) use this specification to study endogenous technical change in a partial-equilibrium model of a competitive industry which faces a given demand function, a given, time-independent interest rate, and is subject to exogenous wage growth. They show that the industry converges to a steadystate equilibrium where productivity growth matches wage growth. In the steady state, the output price, aggregate production, and production per firm are all constant; employment decreases as productivity goes up. Endogenous technical change provides a dynamic mechanism of substitution against labor in response to high and growing wages. 
From a general-equilibrium perspective, this account of the employment effects of wage-induced technical change is problematic as it seems to rest on the assumption of a given function relating output demand to output price. As labor productivity grows, so should income. This should shift the output demand function. Could it be that the negative employment effect of wage growth in the Bester-Petrakis analysis is due to the neglect of such income effects? And what is the role of the assumed exogeneity of wage growth and the interest rate?

To approach these questions, one needs to endogenize income and account for its effects on output demand, i.e., to embed the analysis of endogenous technical change in a general-equilibrium model. We do this by combining the BesterPetrakis model of firm behavior with a household sector à la Ramsey (1928), Cass (1965) or Koopmans (1965). For simplicity we have a single household concerned with his consumption levels in an infinite sequence of periods. From a fixed endowment, this household in each period supplies labor inelastically to the market, and he uses his income from wages and financial claims from past periods to finance his consumption as well as the acquisition of new financial claims. Financial claims are issued by firms needing funds to finance their spending on capital and on productivity improvements with a view to production in the next period. At the level of firms planning for future production there is free entry; following Bester and Petrakis, we assume that at this point all past productivity improvements are in the public domain, i.e., without any spending on productivity improvements, any firm can avail itself of production techniques that yield current productivity levels.

Assuming that wages and interest rates in all periods are determined endogenously by the requirement that all markets clear when all plans are made on the basis of the given sequence of wages and interest rates, we establish the existence of a unique intertemporal general equilibrium. The equilibrium involves stead-state growth from the second period on, with constant output per firm, and a constant, endogenous rate of technical change. Given the fixed supply of labor, total manufactured output increases at the rate of technical change and so do real wages as well as aggregate consumption and aggregate investment. The equilibrium growth rate is one where the income effects of increasing wages on demand just compensate the employment effects of increasing productivity so that aggregate employment is constant at the level corresponding to labor supply. In addition to the Bester-Petrakis effect of wage growth providing incentives for innovation, we also have market-clearing conditions in a world of technical change imposing restrictions on wage growth. Whereas traditional growth models with exogenous technical change have causality running from technical progress to wage growth and Bester and Petrakis have causality running from wage growth to technical change, we treat both, wage growth and productivity growth as endogenous, letting 
them be determined jointly by the conditions for intertemporal general equilibrium.

A key price variable for equilibrating the economy is the rate of interest. On the production side of the economy, for each level of the current interest rate and each level of current productivity, there is a unique future real wage rate such that at the given combination of interest and wage rates the profit-maximizing production-cum-innovation plan of active firms is just compatible with the zeroprofit condition that is implied by free entry. On the consumption side of the economy, for each level of the current interest rate, there is a unique growth rate of consumption that is compatible with consumer optimization. For an equilibrium, the interest rate must adjust so that the consumption growth rate that is implied by consumer optimization is exactly equal to the rate of productivity improvement that is implied by profit maximizing and free entry of firms.

Proceeding to comparative statics and welfare analysis, we find that the equilibrium growth rate in our model is the higher the less discounting of future consumption there is at the household level. We also find that an interest subsidy financed by a tax on (inelastically supplied) labor will increase the equilibrium growth rate as it drives a wedge between the interest that is paid by firms and the interest that is received by the household sector. Up to some level, such an interest subsidy will actually raise welfare because the laissez-faire equilibrium involves too little innovative activity.

Our welfare assessment of too little innovation under laissez-faire is unambiguous because our model has only one relevant externality, the knowledge-spillover externality that arises when innovations between periods $t$ and $t+1$ increase the stock of knowledge that is available at $t+1$, from which subsequent innovative activity starts. In contrast, in some of the models involving oligopolistic or monopolistic competition, this positive externality can be outweighed by negative (pecuniary) externalities from shifting resources out of current consumption where market power makes for a wedge between social marginal benefits and social marginal costs (Aghion and Howitt (1992), Grossman and Helpman (1991), Klingen (1993)). In our model this is not possible because no firm has market power and hence there is no such wedge.

The plan of the paper is as follows. In Section 2 we lay out the details of the model. We begin with the household sector in Section 2.1, continue with the production sector in Section 2.2, discussing first technologies at the level of individual firms, and then the behavior of production aggregates. Finally in Section 2.3 , we specify the concept of intertemporal general competitive equilibrium for the economy that we study. Section 3 presents our main result on the existence of a competitive equilibrium with endogenous growth. Finally, in Section 4, we deal with comparative statics and the welfare analysis of equilibrium growth in 
our model. Section 5 concludes.

\section{The Model}

We study an economy with three objects of exchange, a manufactured good, labor, and bonds, in an infinite sequence of periods $t=1,2, \ldots$ The manufactured good serves for investment as well as consumption. In each period $t$, there are markets for the three objects of exchange. Treating the manufactured good as the numéraire, we let $w_{t}$ denote the real wage and $p_{t}^{b}$ the real bond price at $t$. A bond at $t$ is a claim on one unit of the manufactured good at $t+1$. Working with real interest rates rather than bond prices, we write $p_{t}^{b}=1 /\left(1+r_{t}\right)$ where $r_{t}$ is the real interest rate from $t$ to $t+1$.

\subsection{The Household Sector}

For simplicity we assume that the household sector comprises one household. This household has an initial endowment of $B_{0}$ bonds coming due at $t=1, L$ units of labor in each period $t=1,2, \ldots$, and $100 \%$ of the shares of all firms. The household does not care about leisure. He draws utility from his consumption $c_{t}$ in periods $t=1,2, \ldots$, according to the functional

$$
\sum_{t=1}^{\infty} \beta^{t} \ln c_{t},
$$

where $0<\beta<1$ is a discount factor. Given his initial endowments and given his expectations about the real wages $w_{t}$, real interest rates $r_{t}$, and aggregate dividend distributions $\Pi_{t}$ in all periods $t=1,2, \ldots$, he chooses a strategy for his consumption demand $c_{t}$, labor supply $L_{t}$, and bond demand $B_{t}^{d}$ in $t=1,2, \ldots$ so as to maximize the utility functional (2.1) under the constraints that

$$
\begin{gathered}
c_{t}+B_{t}^{d} /\left(1+r_{t}\right)=w_{t} L_{t}+B_{t-1}^{d}+\Pi_{t}, \\
c_{t} \geq 0, L_{t} \leq L, B_{t}^{d} \geq 0
\end{gathered}
$$

for all $t$, with $B_{0}^{d}=B_{0}$, given. For the given logarithmic utility specification ${ }^{2}$, one has:

${ }^{2}$ Little would change if we used the more general constant relative risk aversion utility

$$
\sum_{t=1}^{\infty} \beta^{t} \frac{c_{t}^{1-\theta}-1}{1-\theta}, \theta \geq 1 .
$$

As usual in infinite-horizon optimal-saving models, the condition $\theta \geq 1$ is needed to ensure the existence of an optimal solution to the household's problem. 
Proposition 1. Given the initial bond endowment $B_{0}$ and the sequence $\left\{w_{t}, r_{t}, \Pi_{t}\right\}$ of real wages, interest rates, and dividend distributions, the household chooses the sequence $\left\{c_{t}, L_{t}, B_{t}^{d}\right\}$ such that for $t=1,2, \ldots$,

$$
\begin{aligned}
c_{t} & =(1-\beta)\left[B_{t-1}^{d}+H_{t}+V_{t}\right] \\
L_{t} & =L \\
B_{t}^{d} & =\left(1+r_{t}\right) \beta\left[B_{t-1}^{d}+H_{t}+V_{t}\right]
\end{aligned}
$$

where

$$
\begin{aligned}
H_{t} & =w_{t} L+\frac{H_{t+1}}{1+r_{t}} \\
& =w_{t} L+\sum_{\tau=1}^{\infty} \prod_{i=0}^{\tau-1}\left(\frac{1}{1+r_{t+i}}\right) w_{t+\tau} L
\end{aligned}
$$

is the consumer's assessment of his human capital and

$$
\begin{aligned}
V_{t} & =\Pi_{t}+\frac{V_{t+1}}{1+r_{t}} \\
& =\Pi_{t}+\sum_{\tau=1}^{\infty} \prod_{i=0}^{\tau-1}\left(\frac{1}{1+r_{t+i}}\right) \Pi_{t+\tau}
\end{aligned}
$$

is the aggregate value of the consumer's share holdings (the discounted current value of outstanding expected dividend distributions) as of date $t$.

The proof of this proposition is standard and is left to the reader. Given that the household does not care about leisure, his planned labor supply is equal to the endowment $L$ for all $t$. As for his consumption, the first-order conditions for $c_{t}, B_{t}^{d}$, and $c_{t+1}$ yield a simple equation

$$
c_{t+1}=\beta\left(1+r_{t}\right) c_{t}
$$

for consumption growth between $t$ and $t+1$. This condition will play a crucial role in the analysis of equilibrium growth.

\subsection{The Production Sector}

\subsubsection{Individual Firms, Technology, and Profit Maximization}

The production sector of the economy is represented by an atomless measure space of firms. From an ex ante perspective, all firms have access to the same technology. 
Production at $t$ requires inputs of manufactured goods at $t-1$ and labor at $t$. Inputs of manufactured goods at $t-1$ serve two purposes: (i) they determine production capacity, and (ii) they affect labor productivity at $t$. Output of a firm at $t$ is equal to

$$
y_{t}=\min \left(x_{t}, a_{t} l_{t}\right),
$$

where $x_{t}$ is production capacity, $a_{t}$ is labor productivity, and $l_{t}$ is the labor input of the firm at date $t$. A production capacity $x_{t}$ at $t$ presumes a capacity investment equal to $\Gamma\left(x_{t}\right)$ units of the manufactured good at $t-1$. The labor productivity of the firm at date $t$ is equal to

$$
a_{t}=A_{t-1}\left(1+q_{t}\right)
$$

here $A_{t-1}$ is an indicator of economy-wide labor productivity at $t-1$, and $q_{t}$ is an indicator of productivity growth at this firm; this productivity growth requires an investment of $K\left(q_{t}\right)$ units of the manufactured good by the firm at date $t-1$. In summary then, at the level of the individual firm, the technology is such that, for a given state $A_{t-1}$ of economy-wide labor productivity at date $t-1$, an input of $\Gamma\left(x_{t}\right)+K\left(q_{t}\right)$ units of the manufactured good at $t-1$ and $l_{t}$ units of labor of $t$ yield an output equal to $\min \left(x_{t}, A_{t-1}\left(1+q_{t}\right) l_{t}\right)$ units of the manufactured good at $t$.

In terms of intellectual property rights, the specification here assumes that any innovation is proprietary knowledge in the period when it is made; however the technology for making it is widely available. Subsequently, as we discuss below, this knowledge becomes embodied in the economy-wide productivity indicator $A$ and is no longer available for proprietary use. Investment in innovation takes place (with reduplication across the firms doing it) because of the possible gains to be reaped during the initial period of availability of the innovation.

In terms of the date $t$ manufactured good as numéraire, a firm that is active at $t$ expects to have a profit equal to

$$
\pi_{t}=\min \left(x_{t}, A_{t-1}\left(1+q_{t}\right) l_{t}\right)-w_{t} l_{t}-\left(1+r_{t-1}\right)\left(\Gamma\left(x_{t}\right)+K\left(q_{t}\right)\right),
$$

corresponding to the difference between its revenue $\min \left(x_{t}, A_{t-1}\left(1+q_{t}\right) l_{t}\right)$ and its costs for labor and prior inputs. The prior inputs $\Gamma\left(x_{t}\right)+K\left(q_{t}\right)$ are financed by issuing bonds, so taking account of interest, the cost is $\left(1+r_{t-1}\right)\left(\Gamma\left(x_{t}\right)+K\left(q_{t}\right)\right)$. The profit, if any, is immediately distributed to the household as the firm's only shareholder.

The input requirement functions $\Gamma\left(x_{t}\right)$ and $K\left(q_{t}\right)$ are assumed to be twice continuously differentiable and to have the following properties:

$$
\begin{aligned}
K(0) & =0, K^{\prime}(0)=0, K^{\prime \prime}(q)>0 \text { for all } q, \\
\Gamma(0) & =0, \Gamma^{\prime}(0)=0, \Gamma^{\prime \prime}(x)>0 \text { for all } x,
\end{aligned}
$$


so investments in innovations and in capacity are both subject to decreasing returns.

We assume that firms take prices as well as economy-wide productivity indicators as given. For given $A_{t-1}, w_{t}$, and $r_{t-1}$, a firm that considers production at $t$ chooses its labor input $l_{t}$, capacity $x_{t}$, and productivity growth rate $q_{t}$ to maximize the profit $\pi_{t}$ as given in (2.6).

Proposition 2. For any $A_{t-1}, w_{t}$, and $r_{t-1}$, the maximum level of profits that a firm can achieve is nonnegative. If $w_{t}>0,1+r_{t-1}>0$, a profit-maximizing plan for production at date $t$ satisfies

$$
x_{t}=A_{t-1}\left(1+q_{t}\right) l_{t} .
$$

If moreover the maximum level of profits that a firm can achieve by producing at date $t$ is zero but a profit-maximizing production plan $\left(l_{t}, x_{t}, q_{t}\right)$ involves $x_{t}>0$, then

$$
\begin{gathered}
x_{t} \operatorname{minimizes} \frac{K\left(q_{t}\right)+\Gamma\left(x_{t}\right)}{x_{t}}, \\
q_{t}>0,
\end{gathered}
$$

and

$$
q_{t} \text { minimizes } \frac{w_{t}}{A_{t-1}\left(1+q_{t}\right)}+\left(1+r_{t-1}\right) C\left(q_{t}\right)
$$

where

$$
C\left(q_{t}\right):=\min _{x} \frac{K\left(q_{t}\right)+\Gamma\left(x_{t}\right)}{x_{t}}
$$

Proof. Nonnegativity of maximum profits follows from the fact that zero production is feasible with zero costs. If $w_{t}>0$ and $1+r_{t-1}>0$, then in view of the Leontief specification (2.5), labor demand will obviously be matched to capacity, yielding $(2.9)$. If $\left(l_{t}, x_{t}, q_{t}\right)$ maximizes profits, $x_{t}>0$, but maximum profits are zero, i.e.,

$$
\begin{aligned}
0=\pi_{t} & =\min \left(x_{t}, A_{t-1}\left(1+q_{t}\right) l_{t}\right)-w_{t} l_{t}-\left(1+r_{t-1}\right)\left(K\left(q_{t}\right)+\Gamma\left(x_{t}\right)\right) \\
& =x_{t}-w_{t} x_{t} / A_{t-1}\left(1+q_{t}\right)-\left(1+r_{t-1}\right)\left(K\left(q_{t}\right)+\Gamma\left(x_{t}\right)\right) \\
& =x_{t}\left[1-w_{t} / A_{t-1}\left(1+q_{t}\right)-\left(1+r_{t-1}\right)\left(K\left(q_{t}\right)+\Gamma\left(x_{t}\right)\right) / x_{t}\right]
\end{aligned}
$$


then $\left(x_{t}, q_{t}\right)$ must be minimizing expected unit costs,

$$
\frac{w_{t}}{A_{t-1}\left(1+q_{t}\right)}+\left(1+r_{t-1}\right) \frac{K\left(q_{t}\right)+\Gamma\left(x_{t}\right)}{x_{t}} .
$$

This immediately yields (2.10) and (2.12). Positivity of $q_{t}$, i.e., (2.11) follows from (2.10) in combination with the observation that, by $(2.7), q_{t}=0$ would imply that $K\left(q_{t}\right)=0$, and, by $(2.8)$, that $\left(K\left(q_{t}\right)+\Gamma\left(x_{t}\right)\right) / x_{t}$ has a unique infimum which is approached as $x_{t}$ goes to zero.

For given data $\left(A_{t-1}, w_{t}, r_{t-1}\right)$, the firm's maximization problem is not convex, so quite generally it will have more than one solution. This issue arises at two levels: (i) If the maximum profit level is zero and this is reached with positive production, then obviously profits are also maximized by choosing not to produce at all. (ii) There might be several distinct profit-maximizing production plans with positive production. Of these two possibilities, the first one is an essential ingredient of the model, arising from the fact that the innovation investment $K\left(q_{t}\right)$ acts like a fixed, i.e., output-independent, cost of production. Whether firms want to produce or not, depends on whether the excess of revenues over variable costs is enough to cover this fixed cost or not; at the boundary between the two regions, they are just indifferent between the two alternatives and as in other models with fixed costs, the transition from one alternative to the other is not continuous.

As for an eventual multiplicity of profit-maximizing production plans with positive production, we note that this depends on the curvature of the unit-cost function $C($.$) that is defined in (2.13). Under the given assumptions (2.7) and$ (2.8), for given $q_{t}>0$, the minimization problem (2.10) that governs the choice of $x_{t}$ has a unique solution, but if the function $C($.$) is not convex, we do not know$ whether this is also true for the minimization problem (2.12) that governs the choice of $q_{t}$. To avoid this difficulty, we follow Bester-Petrakis (1998) and impose the additional conditions:

$$
\begin{aligned}
K^{\prime \prime}(q) & \geq \frac{\left[K^{\prime}(q)\right]^{2}}{2 K(q)} \text { for all } q>0 \\
\Gamma^{\prime \prime}(x) & \geq \frac{2\left[\Gamma^{\prime}(x) x-\Gamma(x)\right]}{x^{2}} \text { for all } x>0 .
\end{aligned}
$$

With these conditions we obtain:

Lemma 1. If $\Gamma($.$) and K($.$) satisfy (2.14) and (2.15) in addition to (2.7) and$ (2.8), then

(a) For any $q>0$, there exists a unique $x(q)>0$ that minimizes $(K(q)+\Gamma(x)) / x$. 
This $x(q)$ is continuous and increasing in $q$, with $\lim _{q \rightarrow 0} x(q)=0$.

(b) The function $C($.$) that is defined in (2.13) is twice continuously differentiable,$ strictly increasing and convex on $\Re_{++}$, with $\lim _{q \rightarrow 0} C(q)=0$ and $\lim _{q \rightarrow 0} C^{\prime}(q)=$ $\sqrt{K^{\prime \prime}(0) \Gamma^{\prime \prime}(0)}$.

The proof of this lemma is given in Appendix 6.1. We immediately use it to state and prove:

Proposition 3. If $\Gamma($.$) and K($.$) satisfy (2.14) and (2.15) in addition to (2.7)$ and (2.8), then

(a) If $w_{t} / A_{t-1}\left(1+r_{t-1}\right)>\sqrt{K^{\prime \prime}(0) \Gamma^{\prime \prime}(0)}$, then the problem (2.12) of minimizing unit cost has a unique solution $q_{t}$; this solution is positive and is characterized by the first-order condition

$$
\frac{w_{t}}{A_{t-1}\left(1+r_{t-1}\right)}=\left(1+q_{t}\right)^{2} C^{\prime}\left(q_{t}\right)
$$

(b) If $w_{t} / A_{t-1}\left(1+r_{t-1}\right) \leq \sqrt{K^{\prime \prime}(0) \Gamma^{\prime \prime}(0)}$, then the problem (2.12) of minimizing unit cost has no solution. An infimum is approached as $q_{t}$ converges to zero (and $x\left(q_{t}\right)$ converges to zero).

Proof. (a) Consider the unit-cost function $q \rightarrow w_{t} / A_{t-1}(1+q)+\left(1+r_{t-1}\right) C(q)$, defined on $\Re_{++}$. This function is differentiable. Its slope is $-w_{t} / A_{t-1}(1+q)^{2}+$ $\left(1+r_{t-1}\right) C^{\prime}(q)$; by Lemma 1 , this is increasing in $q$. If $w_{t} / A_{t-1}\left(1+r_{t-1}\right)>$ $\sqrt{K^{\prime \prime}(0) \Gamma^{\prime \prime}(0)}=\lim _{q \rightarrow 0} C^{\prime}(q)$, this slope is strictly negative for $q$ near zero. For $q$ sufficiently high, this slope is obviously positive, i.e., the unit-cost function is first decreasing and then increasing in the innovation rate $q$. At the point $q>0$ where the slope changes signs, the unit-cost function has a minimum; this is unique and is characterized by the first-order condition (2.16).

(b) $w_{t} / A_{t-1}\left(1+r_{t-1}\right)>\sqrt{K^{\prime \prime}(0) \Gamma^{\prime \prime}(0)}=\lim _{q \rightarrow 0} C^{\prime}(q)$, the unit-cost function $q \rightarrow w_{t} / A_{t-1}(1+q)+\left(1+r_{t-1}\right) C(q)$ is increasing everywhere, so it has no minimum on $\Re_{++}$. An infimum is approached as $q$ goes to zero.

Apart from providing for the regularity of firm behavior that is entailed by convexity of the function $C($.$) , Proposition 3$ shows that under our assumptions innovative activity and production will always go together. Either a firm doesn't produce and then it doesn't innovate, or it produces, and then it always wants to have some innovative activity as well. This latter, rather strong, result is due 
to the (strong) assumption that with $K(0)=0$ and $K^{\prime}(0)=0$, the first unit of innovative additivity is basically costless. As long as a firm plans to have some positive production, it may as well avail itself of this cheap possibility of reducing the cost of its labor.

\subsubsection{The Production Sector: Economy-Wide Aggregates}

Turning to the production sector as a whole, we represent the set of all firms by the set $\Re_{+}$of positive real numbers, using Lebesgue measure to represent the weights of subsets of firms relative to the household. For instance if all firms that are active at some date $t$ have the same production plan $\left(l_{t}, x_{t}, q_{t}\right)$ for this date and if the set of these firms has Lebesgue measure $n_{t}$, we say that aggregate labor demand at $t$ is $n_{t} l_{t}$, which is to be compared with the household's labor supply $L$.

In identifying the set of all firms with $\Re_{+}$, we implicitly introduce a free entry condition. Given that labor supply is bounded, in any given period the set of firms employing more than some $\varepsilon>0$ units of labor and producing more than some $\eta>0$ units of output must have bounded measure and hence must be smaller than the set of all firms. Given that all firms have access to the same technology, this implies that in any equilibrium in any period maximum profits of any firm at equilibrium prices are zero so profits are the same for firms that choose to produce and firms that choose to stay out.

Given that maximum profits in any period $t$ are zero, Propositions 2 and 3 imply that all firms that are active in this period will choose the same production plan $\left(l_{t}, x_{t}, q_{t}\right)$. Let $n_{t}$ be the measure of this set of firms. This measure $n_{t}$ will determine the overall impact of firms producing in period $t$ on markets in periods $t-1$ and $t$. Given the individual production plan $\left(l_{t}, x_{t}, q_{t}\right)$ for date $t$ and the measure $n_{t}$ of active firms, the production sector of the economy expresses an aggregate investment demand for $n_{t}\left(K\left(q_{t}\right)+\Gamma\left(x_{t}\right)\right)$ units of the manufactured good at date $t-1$, in combination with an aggregate bond supply equal to $(1+$ $\left.r_{t-1}\right) n_{t}\left(K\left(q_{t}\right)+\Gamma\left(x_{t}\right)\right)$ units of the manufactured good at date $t$. At date $t$ itself, the production sector expresses an aggregate goods supply equal to $n_{t} x_{t}$ and an aggregate labor demand equal to $n_{t} l_{t}$.

For firms active in period 1, we must make some assumption about initial conditions, in particular about capacities and productivities. Taking our cue from the preceding account of firm behavior in later periods, we assume that as of date 1 , there is a set of measure $n_{1}$ of firms all of which have the same installed capacity $x_{1}$ and labor productivity $a_{1}=A_{0}\left(1+q_{1}\right)$. These firms also have outstanding debt obligations equal to $B_{0}$ on aggregate, or $B_{0} / n_{1}$ per firm; this is the counterpart 
of the household's initial holdings. For notational convenience we write

$$
B_{0}=\left(1+r_{0}\right) n_{1}\left(K\left(q_{1}\right)+\Gamma\left(x_{1}\right)\right),
$$

but otherwise, we treat the firms' prior investments at date 0 as sunk and thus outside the scope of our analysis. Initial conditions of the production sector are thus summarized by the measure $n_{1}$ of active firms, the installed capacity $x_{1}$ and labor productivity $a_{1}=A_{0}\left(1+q_{1}\right)$ of these firms, and their aggregate indebtedness $B_{0}$. To ensure that positive production is feasible at date 1 , we assume that $n_{1}>0$, $x_{1}>0$, and $a_{1}=A_{0}\left(1+q_{1}\right)>0$.

To conclude our account of the production sector, we discuss the evolution of the economy-wide productivity indicators $A_{0}, A_{1}, A_{2}, \ldots$ that determine for each period the base from which further productivity growth starts. Given that for any $t$, all firms that are active at date $t$ will choose the same innovation rate $q_{t}$ and reach the same labor productivity $a_{t}$, it seems reasonable to equate the aggregate productivity indicator $A_{t}$ with this common individual productivity level $a_{t}$ and to set

$$
A_{t}=A_{t-1}\left(1+q_{t}\right)
$$

for $t=1,2, \ldots$, with $A_{0}$ and $q_{1}$ given by initial conditions. This specification reflects the notion, expressed above, that after one period all knowledge becomes embodied in the economy-wide productivity indicator and is no longer available for proprietary use.

At a conceptual level, the specification (2.18) is incomplete because we say nothing about the development of productivity indicators when firms choose different rates of innovation. To do so and to close the model, we might equate $A_{t}$, e.g., to the cross-section average or to the cross-section maximum of the productivity levels $a_{t}^{f}$ reached by different firms $f$ with possibly different choices of productivity growth rates $q_{t}^{f}$. For our purposes here, this does not matter because we shall not actually have to worry about situations where different firms choose different investments in innovation.

\subsection{Intertemporal General Competitive Equilibrium}

We now consider the coordination of activities through prices. We refer to a sequence $\left\{w_{t}, r_{t}\right\}$ of real wages and real interest rates for periods $t=1,2, \ldots$ as a price system. By an allocation we understand a sequence $\left\{c_{t}, L_{t}, B_{t}^{d}, n_{t}, l_{t}, x_{t}, q_{t}\right\}$ comprising a strategy $\left\{c_{t}, L_{t}, B_{t}^{d}\right\}$ for the household and, for each $t$, a measure $n_{t}$ of firms active at $t$, and a production plan $\left(l_{t}, x_{t}, q_{t}\right)$ for these firms. An equilibrium will correspond to price system $\left\{w_{t}, r_{t}\right\}$, an allocation $\left\{c_{t}, L_{t}, B_{t}^{d}, n_{t}, l_{t}, x_{t}, q_{t}\right\}$, and a sequence $\left\{\Pi_{t}, A_{t}\right\}$ of distributed aggregate profits and productivity indicators that satisfy the following conditions: 
(E1) Given the price system $\left\{w_{t}, r_{t}\right\}$ and the distributed-profit sequence $\left\{\Pi_{t}\right\}$, the strategy $\left\{c_{t}, L_{t}, B_{t}^{d}\right\}$ maximizes the household's utility (2.1) under the constraints (2.2) and (2.3).

(E2) For any $t$, the profit distribution $\Pi_{t}$ which the household expects to receive is equal to the actual aggregate of profits of firms active at $t$, i.e.

$$
\Pi_{t}=n_{t}\left[\min \left(x_{t}, A_{t-1}\left(1+q_{t}\right) l_{t}\right)-w_{t} l_{t}-\left(1+r_{t-1}\right)\left(K\left(q_{t}\right)+\Gamma\left(x_{t}\right)\right)\right] .
$$

(E3) Given the productivity indicator $A_{t-1}$, the real wage $w_{t}$, and the real interest rate $r_{t-1}$, for any $t>1$, the production plan $\left(l_{t}, x_{t}, q_{t}\right)$ maximizes the profit (2.6) of a firm active at $t$. For $t=1$, the labor input $l_{1}$ maximizes the profit (2.6) of a firm active at this date.

(E4) Given the productivity indicator $A_{t-1}$, the real wage $w_{t}$, and the real interest rate $r_{t-1}$, for any $t>1$, the profit (2.6) of the profit-maximizing production plan $\left(l_{t}, x_{t}, q_{t}\right)$ is equal to zero.

(E5) For any $t$,

$$
c_{t}+n_{t+1}\left(K\left(q_{t+1}\right)+\Gamma\left(x_{t+1}\right)\right)=n_{t} \min \left(x_{t}, A_{t-1}\left(1+q_{t}\right) l_{t}\right) .
$$

(E6) For any $t, L_{t} \geq n_{t} l_{t}$, with a strict inequality only if $w_{t}=0$.

(E7) For any $t$,

$$
B_{t}^{d}=\left(1+r_{t}\right) n_{t+1}\left(K\left(q_{t+1}\right)+\Gamma\left(x_{t+1}\right)\right) .
$$

(E8) For any $t$, the indicators $A_{t}$ satisfies the updating condition (2.18).

Our concept of equilibrium embodies the usual notions of market clearing and rational expectations, as introduced in Radner's (1972) "equilibrium of plans, prices and price expectations". Agents are assumed to make their plans initially on the basis of expectations about the entire future, the household on the basis of expectations about the price system $\left\{w_{t}, r_{t}\right\}$ and the sequence $\left\{\Pi_{t}\right\}$ of dividend distributions, the firms on the basis of expectations about the price system. Given the array of chosen plans, in each period $t$, markets actually clear at the pair $\left(w_{t}, r_{t}\right)$ and aggregate profits actually amount to the level $\Pi_{t}$ that had been anticipated for this period.

Among the equilibrium conditions, (E1) relates the allocation to the household's utility maximization at given expectations about prices and dividends. Rationality of his expectations about profits and dividends is ensured by (E2). 
Condition (E3) asserts that active firms maximize profits; profit maximization by inactive firms is implied by the zero-profit condition (E4). (E5)-(E7) are the market-clearing conditions, (E5) for manufactured goods, (E6) for labor, and (E7) for bonds. In (E6), we must allow for the possibility of excess supply of labor (at a zero wage) because in view of the strict complementarity between capacity inputs and labor this cannot be ruled out.

A further comment may be warranted about condition (E2). Given that we have said nothing about the prior choices of firms active at $t=1$, it is quite possible for $\Pi_{1}$ to be negative, implying that the household must pay in additional funds to bail out "his" firms. We make this assumption for notational convenience only, because we want to avoid going into details about wage payments or debt service of a bankrupt firm when there is limited liability of shareholders. Given that there is only one household, the specification of liability rules for stocks and bonds at date 1 does not actually matter because regardless of such rules, the sum of wage earnings, debt service and profits received by this household at date 1 must equal the output $\min \left(x_{1}, A_{1} l_{1}\right)$ at this date (Hellwig (1993)). In our treatment this is exactly implied by the budget constraint (2.2), the consistency condition (2.17), (E2) and (E6).

In specifying a consistent circular flow of income, condition (E2) also ensures the validity of Walras' Law in each period $t$, so one of the market-clearing conditions is superfluous. To see this, use (2.2) and (2.19) to write the excess demand for bonds at date $t, B_{t}^{d}-\left(1+r_{t}\right) n_{t+1}\left(K\left(q_{t+1}\right)+\Gamma\left(x_{t+1}\right)\right)$, in the form

$$
\begin{aligned}
&\left(1+r_{t}\right)\left[w_{t} L_{t}+B_{t-1}^{d}+n_{t}\left[\min \left(x_{t}, A_{t-1}\left(1+q_{t}\right) l_{t}\right)-w_{t} l_{t}\right.\right. \\
&\left.\left.-\left(1+r_{t-1}\right)\left(K\left(q_{t}\right)+\Gamma\left(x_{t}\right)\right)\right]-c_{t}-n_{t+1}\left(K\left(q_{t+1}\right)+\Gamma\left(x_{t+1}\right)\right)\right] \\
&=\left(1+r_{t}\right)\left[w_{t}\left(L_{t}-n_{t} l_{t}\right)+B_{t-1}^{d}-n_{t}\left(1+r_{t-1}\right)\left(K\left(q_{t}\right)+\Gamma\left(x_{t}\right)\right)\right] \\
&+n_{t}\left[\min \left(x_{t}, A_{t-1}\left(1+q_{t}\right) l_{t}\right)-c_{t}-n_{t+1}\left(K\left(q_{t+1}\right)+\Gamma\left(x_{t+1}\right)\right)\right]
\end{aligned}
$$

which is automatically equal to zero if (E5) and (E6) hold for $t$ and (E7) holds for $t-1$. Given that the initial condition (2.17) entails the analogue of (E7) for $t=0$, it follows that for every $t$ the bond market condition (E7) is redundant.

\section{Intertemporal Competitive Equilibrium and Growth}

\subsection{Equilibrium Growth: The Main Result}

In the following we develop the main result of our analysis. We give a simple condition for existence of equilibrium. The equilibrium is unique and has a sta- 
tionary structure, involving productivity growth and output growth at a constant rate from date 2 on.

Theorem 3.1. Assume that $\sqrt{K^{\prime \prime}(0) \Gamma^{\prime \prime}(0)}<\beta$. Then there exists a unique equilibrium. The equilibrium has a constant growth rate $q^{*}>0$ so that for $t=2,3, \ldots$, the equilibrium price system and allocation satisfy the following:

(1) $w_{t+1}=\left(1+q^{*}\right) w_{t}$,

(2) $r_{t}=\left(1+q^{*}\right) / \beta-1$,

(3) $q_{t+1}=q^{*}$

(4) $A_{t+1}=\left(1+q^{*}\right) A_{t}$,

(5) $x_{t+1}=x\left(q^{*}\right)=\operatorname{argmin}\left[\left(K\left(q^{*}\right)+\Gamma(x)\right) / x\right]$,

(6) $l_{t+1}=l_{t} /\left(1+q^{*}\right)=x\left(q^{*}\right) / A_{t+1}$,

(7) $n_{t+1}=\left(1+q^{*}\right) n_{t}=A_{t+1} L / x\left(q^{*}\right)$,

(8) $c_{t+1}=\left(1+q^{*}\right) c_{t}=\beta w_{t+1} L+(1-\beta) A_{t+1} L$,

(9) $B_{t}^{d}=\beta\left(A_{t}-w_{t}\right) L=n_{t+1}\left[K\left(q^{*}\right)+\Gamma\left(x\left(q^{*}\right)\right)\right] /\left(1+r_{t}\right)$.

If $\sqrt{K^{\prime \prime}(0) \Gamma^{\prime \prime}(0)} \geq \beta$ an equilibrium fails to exist.

We defer the proof of this result to the next section and first discuss the nature of the equilibrium. The equilibrium has a constant rate of innovation $q^{*}>0$, a constant capacity investment and a constant output per firm. Employment at any one firm decreases at the rate of productivity growth. This is due to the fact that output per firm is constant, so as productivity grows, this output is produced with less labor.

The reduction of employment per firm is compensated by growth in the "number" of firms that are active. The measure $n_{t}$ of the set of active firms grows at the rate $q^{*}$ so aggregate output $n_{t} x_{t}$ grows at the rate $q^{*}$ and aggregate employment $n_{t} x_{t} / A_{t}$ is constant at the level $L$ that corresponds to the household's labor supply.

The growth of productivity and output is matched by real-wage and consumption growth. The intricate interdependence of these four variables stands at the center of the entire growth process. Leaving aside for the moment the role of the interest rate, from the perspective of the production sector, productivity growth and wage growth are related by the conditions that for a given level of current productivity (i) the (expected) future wage determines firms' investments in productivity improvements, and (ii) current productivity improvements determine the future wage at which the active firms will just break even. For a given level of the interest rate, productivity growth and wage growth are jointly (and indeed uniquely) determined by these optimization and free-entry conditions. 
The R\&D investment of the individual firm is indeed financed by inframarginal rents. From the profit function of the individual firm (2.6) in conjunction with (2.9) it is clear that marginal cost pricing requires that for $t>1$

$$
1=\frac{w_{t}}{A_{t-1}\left(1+q_{t}\right)}+\left(1+r_{t-1}\right) \Gamma^{\prime}\left(x_{t}\right) \text {. }
$$

Because an investment in capacity is subject to decreasing returns this gives rise to a "rent", i.e., an excess of revenues over variable production costs. Using $R$ to denote this "rent", we have

$$
R=\int_{0}^{x_{t}}\left[1-\frac{w_{t}}{A_{t-1}\left(1+q_{t}\right)}-\left(1+r_{t-1}\right) \Gamma^{\prime}(\zeta)\right] d \zeta .
$$

At the equilibrium values of $A_{t-1}, w_{t}, r_{t-1}$, and $x_{t}=x\left(q^{*}\right), q_{t}=q^{*}$ with profits equal to zero, this rent is equal to

$$
R^{*}=\int_{0}^{x\left(q^{*}\right)}\left[1-\frac{w_{2}}{A_{1}\left(1+q^{*}\right)}-\left(1+r_{t-1}\right) \Gamma^{\prime}(\zeta)\right] d \zeta
$$

and just covers the innovation cost $\left(1+r_{t-1}\right) K\left(q^{*}\right)$. At the same time

$$
\left(1+r_{t-1}\right) K^{\prime}\left(q^{*}\right)=\frac{d R}{d q}\left(q^{*}\right)=\frac{w_{t} x_{t}}{A_{t-1}\left(1+q^{*}\right)^{2}},
$$

i.e., firms use their innovative activity to raise the inframarginal rent $R$, and at the equilibrium values of $A_{t-1}, w_{t}, r_{t-1}$, and $x_{t}=x\left(q^{*}\right), q_{t}=q^{*}$, the marginal effect of an increase in $q$ on $R$ is just balanced by the marginal cost of this increase.

As in other models of endogenous growth, see, e.g., Grossman and Helpman (1991), Aghion and Howitt (1992), the sustained nature of the growth process rests on the assumption that innovative activity in one period improves the technology not only in production but also in subsequent innovative activity. We use a particularly strong version of this assumption. Not only do we assume that current innovations add to the "stock of knowledge" in the sense of defining the starting point for subsequent investment in innovation. By using manufactured goods rather than labor as inputs into innovative activity, we also ensure that the innovation technology itself partakes of the technological advance: As labor productivity grows, the working hours needed to produce the inputs into innovative activity shrink, which makes it possible to sustain a given positive rate of innovation even as ever more firms engage in innovation and production. Underlying this consideration is the more general issue of how technical progress affects the innovation technology itself. We leave this issue for the moment, but will return 
to it when we discuss the robustness of our analysis in the final section of the paper.

As indicated by (8) and (9), the growth of wages and output also feeds into consumption and investment growth. Equilibrium consumption at any date is equal to a given convex combination of real wage income and aggregate output at this date, so with full employment of labor, equilibrium consumption grows at the same rate $q^{*}$ as labor productivity and the real wage rate. Equilibrium investment at any date $t$ is equal to $n_{t+1}$ times the investment firm, $\left(K\left(q^{*}\right)+\Gamma\left(x\left(q^{*}\right)\right)\right)$, that is required for the innovation rate $q^{*}$ and output capacity $x\left(q^{*}\right)$, so this grows at the same rate $q^{*}$ as the "number" of active firms. This growth in consumption and investment ensures that the growth in aggregate production is matched by a corresponding growth in demand.

However, from the perspective of the consumer's optimization problem, consumption growth is a matter of relative intertemporal prices rather than income growth. As indicated by the first-order condition (2.4) for the consumer's optimization problem, between two periods $t$ and $t+1$, consumption growth at a rate $q_{t}$ is warranted if and only if

$$
1+q_{t}=\beta\left(1+r_{t}\right) .
$$

With $q_{t}=q^{*}$, this shows why the interest rate must satisfy condition (2) in the theorem.

As in other intertemporal models, the interest rate plays a central role in the coordination of activities between the household sector and the production sector. As explained above, for a given productivity level at date $t$, a productivity growth rate $q_{t}$ and a real wage rate $w_{t+1}$ are determined jointly by the firms' optimization and free entry conditions and by the interest rate $r_{t}$. However from the consumer's perspective, a growth rate $q_{t}$ and interest rate $r_{t}$ are compatible only if they also satisfy (3.1). The point of our theorem is that this combination of conditions has exactly one solution.

To see the significance of this point, go back to our discussion of Bester and Petrakis (1998) in the introduction. In their analysis of partial equilibrium in an industry facing a fixed demand function, an interest rate and a constant growth rate of wages are given exogenously, and profit maximization of firms leads (asymptotically) to a rate of innovation which is equal to this growth rate; industry output is asymptotically constant, industry employment is asymptotically declining at a rate equal to the growth rate of wages. Here we allow for productivity growth to feed back into growth of output and demand, where however the growth of consumption demand must satisfy the household's optimality conditions. Given this requirement, the interest rate and the joint growth rate of wages are no longer exogenous, but there is a unique combination of them that is compatible with full 
employment in all periods.

To conclude this introductory discussion of the theorem, we briefly comment on the assumption that $\sqrt{K^{\prime \prime}(0) \Gamma^{\prime \prime}(0)}<\beta$. Recall from Lemma 1 that $\sqrt{K^{\prime \prime}(0) \Gamma^{\prime \prime}(0)}=\lim _{q \rightarrow 0} C^{\prime}(q)$. Suppose that we had an interest rate $r$ so that $\beta(1+r)=1$, and note that by (3.1) this would be the equilibrium interest rate if the equilibrium growth rate were zero. For this specification of $r, \beta>$ $\sqrt{K^{\prime \prime}(0) \Gamma^{\prime \prime}(0)}$ implies $1>(1+r) \lim _{q \rightarrow 0} C^{\prime}(q)$. By Proposition 3, this in turn implies that at the interest rate $r$ and an expected future wage rate $w_{t+1}$ which is not too far below current productivity $A_{t}$ (and that is compatible with overall profits being zero), profit-maximizing firms will choose a strictly positive innovation rate $q_{t+1}$. The assumption that $\beta>\sqrt{K^{\prime \prime}(0) \Gamma^{\prime \prime}(0)}$ effectively ensures that at the market conditions corresponding to zero growth, the marginal cost of investing in labor productivity improvements is less than the marginal benefit of these improvements.

If this marginal condition is not satisfied, i.e., if $\beta \leq \sqrt{K^{\prime \prime}(0) \Gamma^{\prime \prime}(0)}$ and, for $r=1 / \beta-1,1 \leq(1+r) \lim _{q \rightarrow 0} C^{\prime}(q)$, there is no equilibrium with positive growth. Indeed as indicated by the last statement of the proposition, in this case, there is no equilibrium at all. This conclusion is an artefact of the strict convexity of the capacity cost function $\Gamma($.$) in combination with the possibility of free entry; strict$ convexity of $\Gamma$ (.) implies that profit-maximizing, price-taking firms that choose $q=0$ and $x>0$ make positive profits. We might want to think about this as a situation with an unbounded measure of firms each producing an infinitesimal output, but this would transcend the mathematical formalism that we have here.

\subsection{Proof of the Theorem}

We prove the theorem in a sequence of steps, designed to clarify the economics underlying the analysis. We begin by considering the implications of the equilibrium conditions (E1)-(E7) for a price system $\left\{w_{t}, r_{t}\right\}$, an allocation $\left\{c_{t}, L_{t}, B_{t}^{d}, n_{t}, l_{t}, x_{t}, q_{t}\right\}$, and a sequence $\left\{\Pi_{t}, A_{t}\right\}$ of distributed aggregate profits and productivity indicators.

Lemma 2. Let $\left\{w_{t}, r_{t}\right\},\left\{c_{t}, L_{t}, B_{t}^{d}, n_{t}, l_{t}, x_{t}, q_{t}\right\},\left\{\Pi_{t}, A_{t}\right\}$ be an equilibrium. Then for $t=2,3, \ldots, w_{t}>0$ and, $1+r_{t-1}>0$.

Proof. Immediate from conditions (E3) and (E4): If $w_{t}$ were equal to zero, then by choosing $x_{t}>0$ and $q_{t}=0$, a firm producing at $t$ would obtain positive profits. This would also be the case if $1+r_{t-1}$ were equal to zero and the firm chose $x_{t}>0$, close to zero, and $q_{t}$ very large. 
Lemma 3. Let $\left\{w_{t}, r_{t}\right\},\left\{c_{t}, L_{t}, B_{t}^{d}, n_{t}, l_{t}, x_{t}, q_{t}\right\},\left\{\Pi_{t}, A_{t}\right\}$ be an equilibrium. Then for $t=2,3, \ldots, n_{t} l_{t}=L$, and $n_{t} x_{t}=A_{t} L$.

Proof. By Lemma 2, $w_{t}>0$ for $t=2,3, \ldots$ By the market-clearing condition (E6), it follows that $n_{t} l_{t}=L_{t}$ and hence, by Proposition $1, n_{t} l_{t}=L$ for $t=2,3, \ldots$. By Lemma 2, Proposition 2, and (E8), we also have $x_{t}=A_{t} l_{t}$ and hence $n_{t} x_{t}=$ $n_{t} A_{t} l_{t}=A_{t} L$ for $t=2,3, \ldots$.

From Lemma 3, we have $x_{t}>0$ for $t=2,3, \ldots$ By (E3) in combination with Propositions 2 and 3 , it follows $x_{t}=x\left(q_{t}\right)=\operatorname{argmin}\left[\left(K\left(q_{t}\right)+\Gamma(x)\right) / x\right], q_{t}>0$ and $q_{t}=\operatorname{argmin}\left[w_{t} / A_{t}(1+q)+\left(1+r_{t-1}\right) C(q)\right]$. As indicated by the first-order condition (2.16), the minimization determining $q_{t}$ depends only on the ratio

$$
\Omega_{t}:=\frac{w_{t}}{A_{t}\left(1+r_{t-1}\right)} \text {. }
$$

We use this ratio $\Omega_{t}$ as a state variable which determines the behavior of the economy in period $t$, and we study the equilibrium dynamics of the economy through the dynamics of $\Omega_{t}$. For this purpose, we write

$$
\varphi\left(\Omega_{t}, q\right):=\left\{\begin{array}{c}
\Omega_{t} /(1+q)+C(q) \text { if } q>0 \\
\Omega_{t} \text { if } q=0
\end{array}\right.
$$

for the minimum-unit-cost of production at $t$ discounted back to $t-1$, and we set $\widehat{q}\left(\Omega_{t}\right):=\operatorname{argmin} \varphi\left(\Omega_{t}, q\right)$, and $\varphi^{*}\left(\Omega_{t}\right):=\min \varphi\left(\Omega_{t}, q\right)$. Given that $x_{t}>0$ and $q_{t}>0$, (E3) and the zero-profit condition (E4) yield $q_{t}=\widehat{q}\left(\Omega_{t}\right)$, and

$$
1=\left(1+r_{t-1}\right) \varphi^{*}\left(\Omega_{t}\right) \text { for } t=2,3, \ldots
$$

The properties of the functions $\varphi^{*}($.$) and \widehat{q}($.$) are summarized in:$

Lemma 4. (a) The function $\varphi^{*}($.$) is continuous and strictly increasing, with$ $\varphi^{*}\left(\Omega_{t}\right)=\Omega_{t}$ if $\Omega_{t} \leq \sqrt{K^{\prime \prime}(0) \Gamma^{\prime \prime}(0)}, \Omega_{t} /\left(1+\widehat{q}\left(\Omega_{t}\right)\right)<\varphi^{*}\left(\Omega_{t}\right)<\Omega_{t}$ if $\Omega_{t}>$ $\sqrt{K^{\prime \prime}(0) \Gamma^{\prime \prime}(0)}$, and $\lim _{\Omega_{t} \rightarrow \infty} \varphi^{*}\left(\Omega_{t}\right)=\infty$.

(b) The function $\widehat{q}($.$) satisfies \widehat{q}\left(\Omega_{t}\right)=0$ for $\Omega_{t} \leq \sqrt{K^{\prime \prime}(0) \Gamma^{\prime \prime}(0)}$; it is continuous and strictly increasing for $\Omega_{t}>\sqrt{K^{\prime \prime}(0) \Gamma^{\prime \prime}(0)}$, with $\lim _{\Omega_{t} \rightarrow \infty} \widehat{q}\left(\Omega_{t}\right)=\infty$.

The proof of this lemma is immediate from Proposition 3 and the convexity of $C($.$) and is left to the reader.$

In the remainder of the proof of the main theorem, we use the preceding observations to study condition (E5), the market-clearing condition for manufactured 
goods. Lemma 3 implies that for $t=2,3, \ldots$, the supply of the manufactured good at date $t$, i.e., the right-hand side of (2.20), takes the simple form $A_{t} L$. On the demand side, since $x_{t+1}>0$, the investment demand $n_{t+1}\left(K\left(q_{t+1}\right)+\Gamma\left(x_{t+1}\right)\right)$ can be rewritten as $n_{t+1} x_{t+1} C\left(q_{t+1}\right)=A_{t+1} L C\left(\widehat{q}\left(\Omega_{t+1}\right)\right)$. The market-clearing condition (2.20) for the manufactured good at date $t$ is therefore equivalent to the equation $c_{t}+A_{t+1} L C\left(\widehat{q}\left(\Omega_{t+1}\right)\right)=A_{t} L$, or in view of $(\mathrm{E} 8)$,

$$
c_{t}=A_{t} L\left(1-\left(1+\widehat{q}\left(\Omega_{t+1}\right)\right) C\left(\widehat{q}\left(\Omega_{t+1}\right)\right)\right)
$$

From the first-order conditions for the consumer's maximization, we also know that for all $t, c_{t+1}=\beta\left(1+r_{t}\right) c_{t}$, or, in view of $(3.2), c_{t+1}=\beta c_{t} / \varphi^{*}\left(\Omega_{t+1}\right)$. Upon combining this with (3.3), applied to successive $t$, we obtain:

$$
\begin{aligned}
& A_{t+1} L\left(1-\left(1+\widehat{q}\left(\Omega_{t+2}\right)\right) C\left(\widehat{q}\left(\Omega_{t+2}\right)\right)\right. \\
= & \beta A_{t} L\left(1-\left(1+\widehat{q}\left(\Omega_{t+1}\right)\right) C\left(\widehat{q}\left(\Omega_{t+1}\right)\right) / \varphi^{*}\left(\Omega_{t+1}\right) .\right.
\end{aligned}
$$

Again using (E8) to substitute for $A_{t+1}$ and cancelling $A_{t} L$, we find that the succession of market-clearing conditions for the manufactured good in periods $2,3, \ldots$, is equivalent to a first-order difference equation for the "state variable" $\Omega_{t}$ :

$$
\begin{aligned}
& \left(1+\widehat{q}\left(\Omega_{t+1}\right)\right)\left(1-\left(1+\widehat{q}\left(\Omega_{t+2}\right)\right) C\left(\widehat{q}\left(\Omega_{t+2}\right)\right)\right. \\
= & \beta\left(1-\left(1+\widehat{q}\left(\Omega_{t+1}\right)\right) C\left(\widehat{q}\left(\Omega_{t+1}\right)\right) / \varphi^{*}\left(\Omega_{t+1}\right)\right.
\end{aligned}
$$

Lemma 5. The difference equation (3.4) has a unique solution that is compatible with consumption as well as $\Omega_{t}$ being nonnegative for all $t$. The solution satisfies $\Omega_{t}=\Omega^{*}$ for some $\Omega^{*} \geq \beta$ and $t=3,4, \ldots$ If $\beta>\sqrt{K^{\prime \prime}(0) \Gamma^{\prime \prime}(0)}$, then $\beta>$ $\Omega^{*}>\sqrt{K^{\prime \prime}(0) \Gamma^{\prime \prime}(0)}$ and $\widehat{q}\left(\Omega^{*}\right)>0$. If $\beta \leq \sqrt{K^{\prime \prime}(0) \Gamma^{\prime \prime}(0)}$, then $\Omega^{*}=\beta$ and $\widehat{q}\left(\Omega^{*}\right)=0$.

Proof. We first show that the difference equation (3.4) has a unique steady state $\Omega^{*}$ and that this steady state has the indicated properties. Upon setting $\Omega_{t+1}=\Omega_{t+2}=\Omega^{*}$ and rearranging terms, we can rewrite (3.4) as

$$
\left(1+\widehat{q}\left(\Omega^{*}\right)\right) \varphi^{*}\left(\Omega^{*}\right)=\beta .
$$

By Lemma 4, the left-hand side of (3.5) is strictly increasing and continuous in $\Omega^{*}$, taking the value zero if $\Omega^{*}=0$, and taking a value no less than $\beta$ if $\Omega^{*}=\beta$. Hence there is a unique $\Omega^{*} \leq \beta$ that solves (3.5). Lemma 4 also implies that if $\beta>\sqrt{K^{\prime \prime}(0) \Gamma^{\prime \prime}(0)}$, then at $\Omega^{*}=\sqrt{K^{\prime \prime}(0) \Gamma^{\prime \prime}(0)}$, the left-hand side of (3.5) is strictly less than $\beta$, and at $\Omega^{*}=\beta$ the left-hand side of (3.5) is strictly greater than $\beta$, implying that the solution to (3.5) must lie strictly 
between $\sqrt{K^{\prime \prime}(0) \Gamma^{\prime \prime}(0)}$ and $\beta$. If $\beta \leq \sqrt{K^{\prime \prime}(0) \Gamma^{\prime \prime}(0)}$, Lemma 4 implies that the left-hand side of (3.5) takes the value $\beta$ at $\Omega^{*}=\beta$ exactly. Compatibility of the steady state with nonnegative consumption follows from the observation that $\left(1+\widehat{q}\left(\Omega^{*}\right)\right) C\left(\widehat{q}\left(\Omega^{*}\right)\right)<\left(1+\widehat{q}\left(\Omega^{*}\right)\right) \varphi^{*}\left(\Omega^{*}\right)$ so by $(3.5)\left(1+\widehat{q}\left(\Omega^{*}\right)\right) C\left(\widehat{q}\left(\Omega^{*}\right)\right)<1$, and for $\Omega_{t+1}=\Omega^{*},(3.3)$ yields $c_{t}>0$.

We next show that the difference equation (3.4) has no economically meaningful solution other than the steady-state solution $\Omega_{t}=\Omega^{*}$ for all $t$. Suppose to the contrary that there is a solution $\Omega_{2}, \Omega_{3}, \ldots$ that differs from the steady-state solution. Let $\Omega_{t+1}>\Omega^{*}$ for some $t$. Then $\left(1+\widehat{q}\left(\Omega_{t+1}\right)\right) \varphi^{*}\left(\Omega_{t+1}\right)>\beta$, so (3.4) implies

$$
\left(1-\left(1+\widehat{q}\left(\Omega_{t+2}\right)\right) C\left(\widehat{q}\left(\Omega_{t+2}\right)\right)<\left(1-\left(1+\widehat{q}\left(\Omega_{t+1}\right)\right) C\left(\widehat{q}\left(\Omega_{t+1}\right)\right),\right.\right.
$$

hence, by the monotonicity of $\widehat{q}(),. \Omega_{t+2}>\Omega_{t+1}>\Omega^{*}$. By induction, the sequence $\left\{\Omega_{t+k}\right\}, k=1,2, \ldots$ must then be increasing. It cannot converge to a limit. For suppose that it did. Then by taking limits in (3.4), one should find that this limit must be a steady state of this difference equation. Given that the difference equation has only one steady state $\Omega^{*}$ and that $\Omega^{*}<\Omega_{t+1}<\Omega_{t+2} \ldots$, this is impossible. Hence the sequence $\left\{\Omega_{t+k}\right\}$ must be going out of bounds. But then we must have $\left(1-\left(1+\widehat{q}\left(\Omega_{t+k}\right)\right) C\left(\widehat{q}\left(\Omega_{t+k}\right)\right)<0\right.$ and hence, by $(3.3) c_{t+k-1}<0$ for any sufficiently large $k$. This shows that a solution to (3.4) with $\Omega_{t+1}>\Omega^{*}$ for some $t$ is incompatible with the requirement that consumption be nonnegative at all dates.

If instead we have $\Omega_{t+1}<\Omega^{*}$ for some $t$, a precisely symmetric argument shows the sequence $\left\{\Omega_{t+k}\right\}, k=1,2, \ldots$ must then be decreasing. As before, this sequence cannot have a limit because such a limit would have to be a steady state. But then we must have $\Omega_{t+k}<0$ for any sufficiently large $k$, which is impossible. This completes the proof of Lemma 5 .

To complete the proof of the theorem for the case $\beta>\sqrt{K^{\prime \prime}(0) \Gamma^{\prime \prime}(0)}$, we set $q^{*}=\widehat{q}\left(\Omega^{*}\right)$ where $\Omega^{*}>\sqrt{K^{\prime \prime}(0) \Gamma^{\prime \prime}(0)}$ is the unique steady state of the difference equation (3.4). By Lemma $5, q^{*}>0$ as claimed. For $t=2,3, \ldots$,we set $1+r_{t-1}=\left(1+q^{*}\right) / \beta$ so that the consumer's optimization is compatible with consumption growth at the rate $q^{*}$. For $t=2,3, \ldots$, we also set $w_{t+1}=A_{t}\left(1+r_{t}\right) \Omega^{*}$ so that for the given values of $A_{t}, w_{t+1}, r_{t}$, according to Propositions 2 and 3 a firm will actually maximize profits by choosing $q_{t+1}=q^{*}, x_{t+1}=x\left(q^{*}\right)$, and $l_{t+1}=$ $x\left(q^{*}\right) / A_{t}\left(1+q^{*}\right)$. For $t=2,3, \ldots$, we specify the allocation as in $(3)-(9)$. Given this specification, for $t=2,3, \ldots$, the equilibrium conditions (E1)-(E8) are easily verified.

The first period, $t=1$, requires special treatment because we have no guaran- 
tee that $n_{1} x_{1}=A_{1} L$. Considering the market-clearing condition for the manufactured good in period 1 , we note that goods supply is exogenously given as $\min \left(n_{1} x_{1}, A_{1} L\right)$. Consumption demand $c_{1}$ can be equated to $c_{2} / \beta\left(1+r_{1}\right)$, where, from (3.3) with $\Omega_{3}=\Omega^{*}, c_{2}=A_{2} L\left(1-\left(1+\widehat{q}\left(\Omega^{*}\right)\right) C\left(\widehat{q}\left(\Omega^{*}\right)\right)\right)$. Investment demand at $t=1$ is $A_{2} L C\left(\widehat{q}\left(\Omega_{2}\right)\right)$ and, by the zero-profit condition (3.2), $1 /\left(1+r_{1}\right)=\varphi^{*}\left(\Omega_{2}\right)$. Given that $A_{2}=A_{1}\left(1+\widehat{q}\left(\Omega_{2}\right)\right)$, the market-clearing condition for date 1 can now be written as

$\min \left(n_{1} x_{1}, A_{1} L\right)=A_{1} L\left(1+\widehat{q}\left(\Omega_{2}\right)\right)\left[\varphi^{*}\left(\Omega_{2}\right)\left(1-\left(1+\widehat{q}\left(\Omega^{*}\right)\right) C\left(\widehat{q}\left(\Omega^{*}\right)\right)\right) / \beta+C\left(\widehat{q}\left(\Omega_{2}\right)\right)\right]$

By familiar arguments, the right-hand side is continuous and strictly increasing in $\Omega_{2}$, and there exists a unique $\Omega_{2}$ for which this market-clearing condition is satisfied. Upon using this value of $\Omega_{2}$ to specify $w_{2}, r_{1}, q_{2}, x_{2}, n_{2}, l_{2}, c_{1}, B_{1}^{d}$, and setting $l_{1}=\min \left(x_{1} / A_{1}, L / n_{1}\right)$, one finds that the specification of the equilibrium allocation is complete.

For the case $\beta \leq \sqrt{K^{\prime \prime}(0) \Gamma^{\prime \prime}(0)}$, we note that in an equilibrium on the one hand, by Lemma 5 the "state variables" $\Omega_{t}$ would have to take the value $\beta$, with $\widehat{q}\left(\Omega_{t}\right)=\widehat{q}(\beta)=0$ for $t=2,3, \ldots$. On the other hand, by Lemma 3 and Proposition 2, we should have $x_{t}>0$ and $q_{t}=\widehat{q}\left(\Omega_{t}\right)>0$ for all $t$. In this case then the assumption that an equilibrium exists leads to a contradiction. This completes the proof of the theorem.

\section{Comparative Statics and Welfare Analysis}

\subsection{Comparative Statics}

In this section we consider the dependence of the equilibrium growth rate $q^{*}$ on the parameter of the model. We also consider the possibility of affecting the equilibrium growth rate by measures of public policy. We begin with a result on the comparative statics properties of the equilibrium under laissez-faire that was the subject of Section 3. Our first result concerns the influence of consumer discounting.

Proposition 4. The equilibrium growth rate $q^{*}$ and the equilibrium output per firm $x\left(q^{*}\right)$ are the higher, the higher is $\beta$.

Proof. Recall from the proof of the theorem that $q^{*}=\hat{q}\left(\Omega^{*}\right)$ where $\Omega^{*}$ is the unique value of the "state variable" $\Omega_{t}$ that satisfies the steady-state condition $\beta=\left(1+\hat{q}\left(\Omega^{*}\right)\right) \varphi^{*}\left(\Omega^{*}\right)$, i.e., condition (3.5). As $\beta$ goes up, so must $\left(1+\hat{q}\left(\Omega^{*}\right)\right) \varphi^{*}\left(\Omega^{*}\right)$. Given that, by Lemma $4,\left(1+\hat{q}\left(\Omega^{*}\right)\right) \varphi^{*}\left(\Omega^{*}\right)$ is increasing in 
$\Omega^{*}$. This implies that the solution $\Omega^{*}$ to $(3.5)$ must increase with $\beta$. Since, by Lemma 4 and Proposition 3, $\hat{q}($.$) and x($.$) are strictly increasing functions, the$ proposition follows immediately.

The intuition of this proposition is the following. A higher $\beta$ means that the household values future consumption more highly, and for a given value of the interest rate, he is prepared to have a higher growth rate of consumption. From the production side of the economy however, a higher growth rate requires a reduction in the interest rate. This reduction will reduce the consumption growth rate desired by the household, but not enough to outweigh the direct effect of having a higher $\beta$ and less discounting by the household. In the equilibrium corresponding to the higher $\beta$, there must be both, a lower interest rate and a higher growth rate, in accordance with the implications of profit maximization and zero profits of firms. The increase in firm spending on innovative activity raises their fixed costs which in turn raises the level of output at which they minimize average costs.

Similar comparative-statics results are available with respect to productivity parameters if we introduce such parameters into the cost functions $K($.$) and \Gamma($.$) .$ Suppose for instance that $K(q) \equiv q^{2} / \kappa$ and $\Gamma(x) \equiv x^{2} / \gamma$ so that innovation costs decrease as $\kappa$ increases and capacity costs decrease as $\gamma$ increases. Then for $q>0$, minimal unit cost is equal to $C(q)=q /(\kappa \gamma)^{1 / 2}$, and for $\Omega>1 /(\kappa \gamma)^{1 / 2}$ one has $\hat{q}(\Omega)=\Omega^{1 / 2}(\kappa \gamma)^{1 / 4}-1$, which is increasing in $\kappa \gamma$. A similar argument as before shows that in this case, the equilibrium growth rate $q^{*}$ is increasing in $\kappa$ and $\gamma$. Thus $q^{*}$ is positively affected by positive shifts in the productivity of innovative investments as well as capacity investments.

Turning away from the comparative statics of the laissez-faire system that we have studied so far, we now consider the impact of fiscal policy in our model. The fiscal policy measure we consider involves a government subsidy for bonds, financed by a tax on labor income. With inelastic labor supply of the household, the tax on labor income is nondistortionary, so we really are looking at the effects of an interest rate subsidy. We assume that the subsidy rate is the same in all periods. We denote this rate by $\sigma$. Letting $r_{t}$ denote the interest rate contracted and paid by firms borrowing at date $t$, as before, we specify the household's rate of return on these bonds as $r_{t}+\sigma$.

For a given price system $\left\{w_{t}, r_{t}\right\}$ as seen by firms, the production side of the economy is unaffected by this fiscal policy. The household is affected because (i) for a given sequence of interest rates $\left\{r_{t}\right\}$, the interest rate subsidy affects his desired rate of consumption growth, and (ii) both the interest rate subsidy and the labor income tax have income effects. If the government budget is balanced, the income effects will just neutralize each other, and it suffices to consider the incentive effects of the interest rate subsidy. With the subsidy, the first-order 
condition indicating the household's desired consumption growth is found to be:

$$
c_{t+1}=\beta\left(1+r_{t}+\sigma\right) c_{t},
$$

which generalizes (2.4) to the case $\sigma \neq 0$. As before, this condition can be matched with conditions from the production side of the economy to determine the implications of market clearing for manufactured goods in successive periods. Without going through the details, we note that the same argument as before can be used to rule out non-steady-state equilibria. As for the steady state, we find that the equilibrium steady-state interest rate and growth rate, which we denote by $r(\sigma)$ and $q(\sigma)$ must be such that

$$
1+q(\sigma)=\beta(1+r(\sigma)+\sigma)
$$

so the household's optimization is indeed compatible with growth at the rate $q(\sigma)$. From the preceding sections' analysis of firm behavior, we also know that $q(\sigma)=\hat{q}(\Omega(\sigma))$, where for the given $\sigma, \Omega(\sigma)$ denotes the steady-state equilibrium value of the "state variable" $\Omega_{t}$ which determines optimal production plans for period $t$. Using the zero-profit condition (3.2) as before to substitute for $1+r(\sigma)$ and rearranging terms, we can rewrite (4.1) as

$$
\beta=(1+\hat{q}(\Omega(\sigma))-\beta \sigma) \varphi^{*}(\Omega(\sigma)),
$$

which generalizes (3.5) to the case $\sigma \neq 0$. The right-hand side of (4.2) is again increasing in $\Omega(\sigma)$, so again there cannot be more than one steady state. Moreover the direct effect of $\sigma$ is to reduce the right-hand side of (4.2), requiring a compensating increase in $\Omega(\sigma)$. This yields:

Proposition 5. The equilibrium growth rate $q(\sigma)$ and the equilibrium output per firm $x(q(\sigma))$ are the higher, the higher is $\sigma$. The equilibrium interest rate paid by firms, $r(\sigma)$, decreases with $\sigma$.

The interest rate subsidy also serves to expand the range of parameters for which an equilibrium exists. Whereas our main theorem gave $\beta>\sqrt{K^{\prime \prime}(0) \Gamma^{\prime \prime}(0)}$ as necessary and sufficient condition for equilibrium existence, this condition is now modified to $\beta>\sqrt{K^{\prime \prime}(0) \Gamma^{\prime \prime}(0)} /\left(1+\sigma \sqrt{K^{\prime \prime}(0) \Gamma^{\prime \prime}(0)}\right)$. The argument establishing existence and uniqueness of equilibrium under this condition with $\sigma \neq 0$ is practically the same as for the case $\sigma=0$. We leave this argument to the reader. 


\subsection{Optimal Growth}

To conclude the analysis of our model, we consider the welfare properties of equilibrium. Given that the model has only one household, the choice of a welfare criterion is straightforward: We evaluate allocations according the discounted present value of utility that they yield to the household.

In comparing allocations, we restrict attention to those allocations that have the same structural properties as the equilibrium allocations in our analysis, namely in each period, the set of all firms is partitioned into a subset of active firms and a subset of inactive firms, and all active firms choose the same production plan. We do not allow for allocations that involve, e.g., a very small set of firms investing a lot in innovations as a way of enhancing the "stock of knowledge" available in subsequent periods without so much reduplication of innovative activity. Such allocations would require a lot of explicit coordination across firms to determine who innovates a lot and who does not. When the decisions of firms are decentralized and any "social planner" is restricted to using taxes and subsidies to affect the incentives that firms have, such coordination mechanisms are not available. $^{3}$

Given these considerations, the welfare maximization problem can be written as:

$$
\operatorname{Max} \sum_{t=1}^{\infty} \beta^{t} \ln c_{t}
$$

subject to the constraints that

$$
c_{t}+n_{t+1}\left[K\left(q_{t+1}\right)+\Gamma\left(x_{t+1}\right)\right]=\min \left(n_{t} x_{t}, A_{t} L\right),
$$

and

$$
A_{t+1}=\left(1+q_{t+1}\right) A_{t}
$$

for all $t$, where $n_{1}>0, x_{1}>0, A_{1}>0$ are again given. The first constraint requires that consumption and investment in each period are covered by that period's output, the second constraint restates our specification for productivity growth. Full use of available labor has already been incorporated as this is obviously necessary for welfare optimality.

\footnotetext{
${ }^{3}$ To avoid the difficulty mentioned here, we might also assume that the economy-wide productity indicator $A_{t+1}$ at date $t+1$ responds to a cross-section average of innovations at $t$. However, this would require some account of what happens at $t+1$ to firms that have invested more than the average in innovations at $t$.
} 
Proposition 6. The welfare maximization problem (4.3) has a unique solution $\left\{c_{t}, n_{t}, x_{t}, q_{t}, A_{t}\right\}$. There is a constant growth rate $q^{* *}$ so that for $t=2,3, \ldots$, the optimal allocation satisfies the following:

$$
\begin{aligned}
q_{t+1} & =q^{* *} \\
A_{t+1} & =\left(1+q^{* *}\right) A_{t}, \\
x_{t+1} & =x\left(q^{* *}\right)=\arg \min \left[\left(K\left(q^{* *}\right)+\Gamma(x)\right) / x\right], \\
n_{t+1} & =\left(1+q^{* *}\right) n_{t}=A_{t+1} L / x\left(q^{* *}\right) \\
c_{t+1} & =\left(1+q^{* *}\right) n_{t}=A_{t} L\left(1-\left(1+q^{* *}\right) C\left(q^{* *}\right) .\right.
\end{aligned}
$$

The optimal growth rate $q^{* *}$ satisfies the first-order condition:

$$
C\left(q^{* *}\right)+\left(1+q^{* *}\right) C^{\prime}\left(q^{* *}\right)=\beta\left(1+q^{* *}\right)\left[\frac{1}{\left(1+q^{* *}\right)^{2}}+C^{\prime}\left(q^{* *}\right)\right] .
$$

The proof of this proposition is routine and is given in Appendix 6.2. Here we concentrate on the intuition for the condition determining the optimal growth rate. By simple efficiency considerations, for $t=2,3, \ldots$, we must have $n_{t} x_{t}=A_{t} L$ and $x_{t}=x\left(q_{t}\right)$ so that there is full employment of all resources and moreover the trade-off between "number" and size of active firms is handled so as to minimize unit costs. Given these conditions, we can rewrite the feasibility constraint (4.4) for the use of the manufactured good at date $t$ in the form

$$
c_{t}+A_{t+1} L C\left(q_{t+1}\right)=A_{t} L
$$

or

$$
c_{t}+A_{t} L\left(1+q_{t+1}\right) C\left(q_{t+1}\right)=A_{t} L
$$

Now consider the effects of an increase in $q_{t+1}$, combined with a decrease in $q_{t+2}$ so that $A_{t+2}$ (as well as $A_{t+3}, A_{t+4}$, etc.) is unaffected. The increase in $q_{t+1}$ requires additional investment resources and lowers consumption at date $t$. The two terms on the left-hand side of the first-order condition (4.5) indicate this cost effect from the perspective of period $t$ at the margin, normalized by $A_{t} L$. The first term, $C\left(q^{* *}\right)$, corresponds to the additional investment needs that arise as $q_{t+1}$ increases, the productivity $A_{t+1}=A_{t}\left(1+q_{t+1}\right)$ increases, so at the given efficient per-firm capacity $x\left(q_{t+1}\right)$ additional firms with additional investment must become active to provide for full employment of labor at $t+1$. The second term, $\left(1+q^{* *}\right) C^{\prime}\left(q^{* *}\right)$, measure the direct effect of the increase in $q_{t+1}$ on the investment needs of given firms.

The right-hand side of first-order condition (4.5) measures the marginal benefits from the increase in $q_{t+1}$. These benefits arise in period $t+1$. Given that 
we look at the situation from the perspective of period $t$, the marginal benefits must be discounted back by one period, hence the $\beta$ before both terms. Since whatever happens concerns an economy that is $\left(1+q_{t+1}\right)$ as large at $t+1$ as at $t$, the marginal benefits per firm must also be multiplied by this factor. At the level of the individual firm, there are then two sources of benefits of the increase in $q_{t+1}$ : First, labor inputs per unit of output are reduced so more output can be produced; this is represented by the first term in square brackets. Second, the "knowledge spillover" from productivity growth between $t$ and $t+1$ permits a decrease in $q_{t+2}$ resulting in lower investment; this is represented by the second term in square brackets. Both these benefits serve to increase consumption at $t+1$. Condition (4.5) requires that after discounting back by one period, they are at the margin just equal to the cost of an increase in $q_{t+1}$.

A comparison of the optimal-growth condition (4.5) with the conditions for equilibrium growth under laissez-faire yields:

Proposition 7. The equilibrium growth rate $q^{*}$ under laissez-faire is strictly less than the optimal growth rate $q^{* *}$.

Proof. The equilibrium growth rate $q^{*}$ satisfies the first-order condition for $\hat{q}\left(\Omega^{*}\right)$,

$$
\Omega^{*}=\left(1+q^{*}\right)^{2} C^{\prime}\left(q^{*}\right)
$$

as well as the steady-state condition

$$
\beta=\left(1+q^{*}\right) \varphi^{*}\left(\Omega^{*}\right)
$$

Given the definition of $\varphi^{*}($.$) , the latter is equivalent to the requirement that$

$$
\beta=\Omega^{*}+\left(1+q^{*}\right) C\left(q^{*}\right) .
$$

Upon using (4.6) to substitute for $\Omega^{*}$ and rearranging terms, this yields:

$$
C\left(q^{*}\right)+\left(1+q^{*}\right) C^{\prime}\left(q^{*}\right)=\beta \frac{1}{1+q^{*}} .
$$

Upon comparing this with the condition for $q^{* *}$, one easily finds that $q^{*}<q^{* *}$.

The crucial difference between the condition for $q^{*}$ and the condition for $q^{* *}$ is that the former does not take account of the intertemporal spillover effect from current productivity growth on the starting point of future innovative and productive activity. Condition (4.7) has no equivalent of the second term on the right-hand side of (4.5). 
A natural question is whether this problem can be resolved by an interest rate subsidy. The answer to this question is affirmative. If the interest rate subsidy is chosen so as to just account for the "knowledge spillover" externality, the resulting equilibrium will maximize welfare (4.3) under the constraint (4.4)

Proposition 8. For an interest rate subsidy

$$
\sigma^{* *}=\frac{\left(1+q^{* *}\right)^{2} C^{\prime}\left(q^{* *}\right)}{C\left(q^{* *}\right)+\left(1+q^{* *}\right) C^{\prime}\left(q^{* *}\right)}
$$

the equilibrium growth rate $q\left(\sigma^{* *}\right)$ is equal to the optimal growth rate $q^{* *}$, and the equilibrium allocation is equal to the optimal allocation.

Proof. By (4.2), for any $\sigma$, we have

$$
\beta+\beta \sigma \varphi^{*}(\Omega(\sigma))=(1+q(\sigma)) \varphi^{*}(\Omega(\sigma)) .
$$

By the definition of $\varphi^{*}($.$) , and the first-order condition for q(\sigma)=\hat{q}(\Omega(\sigma))$, we also have

$$
\varphi^{*}(\Omega(\sigma))=C(q(\sigma))+(1+q(\sigma)) C^{\prime}(q(\sigma)),
$$

hence

$$
\frac{\beta\left(1+\sigma \varphi^{*}(\Omega(\sigma))\right)}{(1+q(\sigma))}=\left(C(q(\sigma))+(1+q(\sigma)) C^{\prime}(q(\sigma))\right) .
$$

Upon substituting from (4.8) into (4.9) and comparing with (4.5), one immediately sees that $q\left(\sigma^{* *}\right)=q^{* *}$. Given this observation, the optimality of the equilibrium allocation at the interest rate subsidy $\sigma^{* *}$ is easily verified.

\section{Concluding Remarks}

To conclude the paper, we briefly discuss the robustness of our findings to changes in the specification of the model that we use. Three points seem important: First, what is the role of the assumption that there is one infinitely-lived household? Secondly, what is the role of the assumption that capacity investments and labor are strict complements in production? Thirdly, what is the role of the assumption that innovations require investments of manufactured goods rather than labor? Each of these assumptions is quite special, so it is important to see how robust our findings may be if we generalize them. We discuss this for each one in turn. 
The assumption that there is one infinitely-lived household seems to be important in tying the equilibrium growth rate of the economy to intertemporal consumption choices. As far as the household sector is concerned, equilibrium consumption growth and interest rates in our analysis are linked together by condition (3.1), which derives the household's desired consumption growth from marginal considerations concerning the intertemporal allocation of consumption. The question of robustness with respect to this specification can be posed at two levels: (i) For a given population involving several infinitely-lived consumers, one can ask whether the coordination of their intertemporal consumption choices through the price mechanism works sufficiently well to maintain the link between the growth of aggregate consumption and individual optimization at equilibrium prices that we use in (3.1). (ii) For a growing population of finitely- or infinitelylived consumers, shouldn't the growth rate of aggregate consumption depend on population growth rather than individual optimization? The first of these question is not specific to growth models, it affects all macroeconomic models that represent the household sector by one person and use the conditions for that person's optimization to obtain restrictions on economic aggregates. On this question we have nothing to add. The second question is more specific to our analysis as it directly concerns the determination of equilibrium growth.

On this question, one easily verifies that, e.g., in an overlapping-generations model with finitely-lived consumers, the aggregate growth of the economy will be equal to the growth of the labor force in efficiency units, i.e., to roughly the sum of population growth and productivity growth. In terms of equilibrium consumption demand, both growth rates matter: Whereas the population growth rate comes in as an additional factor determining the intertemporal equilibrium, it does not entirely displace the productivity growth rate. As a result, the very simple relation (3.1) between equilibrium productivity growth and interest rates has to be replaced by a more complex relation, which also contains the ratio $w_{t+1} / A_{t}$ of real wages and productivity, but apart from its being more complicated, the analysis of equilibrium growth developed in Section 3 goes through without change.

The second question above concerns the role of complementarity in production. This assumption is important for the treatment of wages. In each period other than possibly the first, installed capacity is just equal to full-employment capacity. This ensures that in each period the labor market clears. The role of the wage is not so much to clear the labor market by changing supply and demand in the current period. It is rather that expectations of the wage at prior dates guide prior entry, capacity and innovation investment decisions. In contrast, in a world with ex post variability of labor inputs per capacity unit, the market-clearing role of wages in current labor market will also be important. Specifically, in each period the real wage must be equal to the marginal product of labor at installed 
capacity, a consideration which did not play a role here.

On this question again though, one easily verifies that our conclusions are robust, except that convergence to the steady state may take more than one period. The crucial technological assumption concerns the existence of inframarginal returns, not the complementarity between labor and capacity investments. Suppose for example that at the firm level production is governed by a neoclassical production function $F$, with inputs capital and efficiency units of labor, and suppose that $F$ is homogeneous of degree $\alpha \in(0,1)$ in these two inputs. If the firm's input of efficiency units of labor takes the form, $A_{t-1}\left(1+q_{t}\right) l_{t}$, where, as in the analysis here, $A_{t-1}$ is an economy-wide productivity index for date $t-1, q_{t}$ is a chosen innovation level presuming an innovation investment of $K\left(q_{t}\right)$ units of the manufactured good at date $t-1$, and $l_{t}$ is labor input, one can again establish existence of steady-state equilibria with positive endogenous growth where the fact that $\alpha$ is strictly less than one provides firms with inframarginal returns which serve to finance the innovation investment. Given that steady-state production plans involve the determination of capital-labor ratios as well as firm scales and firm innovation investments, the analysis is again more complicated, but does not involve any fundamental difficulty.

Our third question concerns the specification of inputs for innovation investment. As mentioned in our discussion of the main theorem, the assumption that innovation investment uses the manufactured good rather than labor as an input provides a way to introduce technical progress into the innovation process itself. If instead we specify the innovation cost $K(q)$ in units of labor, the economy cannot exhibit sustained growth because there is no technical progress in the innovation process itself.

It is useful to think about this issue in more abstract terms, from an Austrian perspective where all prior investments, whether in capacity or in innovation, are traced back to a sequence of dated labor inputs. From this perspective, different sequences of innovation investments correspond to different production choices about the transformation of dated-labor-input sequences into outputs. Steadystate productivity growth at a positive rate would require that for one unit of output produced at, say date $t+1$ as opposed to date $t$, the entire sequence of dated labor inputs can be less by a factor $q /(1+q)$. This requires in particular, that in terms of labor inputs the productivity of innovation investments grows at the same rate $q$ as everything else. With a fixed function $K($.$) , specified in units$ of labor, this is not satisfied.

In contrast to our paper, most of the literature, e.g., the work of Aghion and Howitt (1992) or Grossman and Helpman (1991), assumes that innovative activity is based on labor as an input. In this literature, the issue of productivity improvements in innovation itself would also seem to arise. However this issue 
is handled implicitly, through the assumption that growth takes place inside of firms rather than replication. If we allowed for innovation to affect the unit-costminimizing scale of firm production as well as the level of labor productivity, this would provide room for sustained growth with labor as well as manufactured goods serving as inputs into innovation. Further research in this direction would seem to hold some promise of insight into the relation between innovation technologies and the development of the distribution of production units and firms in the growth process. 


\section{Appendix}

\subsection{Proof of Lemma 1}

(a) Given that $q>0,(2.7)$ implies $K(q)>0$. Hence $\lim _{x \rightarrow 0}(K(q)+\Gamma(x)) / x=\infty$. From (2.8) and (2.15), we also have $\lim _{x \rightarrow \infty}(K(q)+\Gamma(x)) / x=\infty$. For $q>0$, a minimum of the expression $(K(q)+\Gamma(x)) / x$ on $(0, \infty)$ will therefore exist, and the first-order condition for this minimum,

$$
x \Gamma^{\prime}(x)-K(q)-\Gamma(x)=0,
$$

will have a solution. Given that the left-hand side of this condition is strictly increasing in $x$ (with slope $x \Gamma^{\prime \prime}(x)$ ), this solution is unique. Refer to it as $x(q)$. For $x<x(q)$, the left-hand side of $(6.1)$ is negative, so $(K(q)+\Gamma(x)) / x$ is decreasing; for $x>x(q)$, the left-hand side of (6.1) is positive, so $(K(q)+\Gamma(x)) / x$ is increasing in $x$. Thus $(K(q)+\Gamma(x)) / x$ has a unique minimum at $x(q)$. By the implicit function theorem, the function $x($.$) defined by (6.1) is differentiable, with$ derivative

$$
\frac{d x}{d q}=\frac{K^{\prime}(q)}{x(q) \Gamma^{\prime \prime}(x(q))}
$$

which by (2.8) is positive, so $x($.$) is increasing. As q$ goes to zero, $x(q)$ decreases to a limit. This limit must satisfy the equation $x \Gamma^{\prime}(x)=\Gamma(x)$, obtained by taking limits in (6.1). Again by (2.8), it follows that this limit is equal to zero.

(b) By (a), for $q>0, C(q)$ is well defined. By the envelope theorem, $C($.$) is$ continuously differentiable at $q>0$, and the derivative satisfies

$$
C^{\prime}(q)=\frac{K^{\prime}(q)}{x(q)}
$$

Using (6.2), this can again be differentiated to yield

$$
C^{\prime \prime}(q)=\frac{K^{\prime \prime}(q) x(q)-K^{\prime}(q) x^{\prime}(q)}{[x(q)]^{2}}
$$

which is nonnegative if (2.14) and (2.15) hold. The first part of the lemma is thus proved. To show that $\lim _{q \rightarrow 0} C(q)=0$, it suffices to observe that for any $q>0$, one has $0<C(q) \leq[K(q)+\Gamma(\sqrt{K(q)})] / \sqrt{K(q)}$. As $q$ and $K(q)$ go to zero, so obviously will $K(q) / \sqrt{K(q)}=\sqrt{K(q)}, \Gamma(\sqrt{K(q)}) / \sqrt{K(q)}$, and with them 
$C(q)$. To prove that $\lim _{q \rightarrow 0} C^{\prime}(q)=\sqrt{K^{\prime \prime}(0) \Gamma^{\prime \prime}(0)}$, use l'Hôspital's rule to take limits in (6.3) as

$$
\lim _{q \rightarrow 0} C^{\prime}(q)=\frac{K^{\prime \prime}(0)}{\lim _{q \rightarrow 0}(d x / d q)}
$$

or

$$
\left[\lim _{q \rightarrow 0} C^{\prime}(q)\right]\left[\lim _{q \rightarrow 0}(d x / d q)\right]=K^{\prime \prime}(0) .
$$

From (6.2) and (6.3), we also have $\Gamma^{\prime \prime}(x(q)) d x / d q=C^{\prime}(q)$, hence $\Gamma^{\prime \prime}(0) \lim _{q \rightarrow 0} d x / d q=\lim _{q \rightarrow 0} C^{\prime}(q)$. Upon multiplying (6.4) by $\Gamma^{\prime \prime}(0)$, one obtains $\left[\lim _{q \rightarrow 0} C^{\prime}(q)\right]^{2}=K^{\prime \prime}(0) \Gamma^{\prime \prime}(0)$, as desired.

\subsection{Proof of Proposition 6}

We begin with a preliminary lemma, which provides the analogue of Lemmas 2 and 3 in the proof of the main result. The proof of this lemma is trivial and is left to the reader.

Lemma 6. Suppose that $\left\{c_{t}, n_{t}, x_{t}, q_{t}, A_{t}\right\}$ solves the welfare maximization problem (4.3). Then for $t=2,3, \ldots, x_{t}=x\left(q_{t}\right)=\arg \min \left[\left(K\left(q_{t}\right)+\Gamma(x)\right) / x\right]$, and $n_{t} x_{t}=A_{t} L$. Moreover $\left\{c_{t}, q_{t}, A_{t}\right\}$ solves the problem

$$
\operatorname{Max} \sum_{t=1}^{\infty} \beta^{t} \ln c_{t}
$$

subject to the constraints that

$$
c_{1}+A_{1} L\left(1+q_{2}\right) C\left(q_{2}\right)=\min \left(n_{1} x_{1}, A_{1} L\right),
$$

and, for $t=2,3, \ldots$,

$$
\left.c_{t}+A_{t} L\left(1+q_{t+1}\right) C\left(q_{t+1}\right)\right)=A_{t} L
$$

and

$$
A_{t+1}=\left(1+q_{t+1}\right) A_{t}
$$

Conversely, if $\left\{c_{t}, q_{t}, A_{t}\right\}$ solves problem (6.5), then by setting $x_{t}=x\left(q_{t}\right)$ and $n_{t}=$ $A_{t} L / x\left(q_{t}\right)$, one obtains a solution $\left\{c_{t}, n_{t}, x_{t}, q_{t}, A_{t}\right\}$ to the welfare maximization problem (4.3). 
Lemma 7. Problem (6.5) has a solution.

Proof. Consider the set of programs $\left\{c_{t}, q_{t}, A_{t}\right\}$ that satisfy the constraints (6.6)(6.8) for the given $n_{1}, x_{1}, A_{1}$. Nonnegativity of consumption implies that for all $t$, $q_{t}$ is bounded above by $\bar{q}$, where $(1+\bar{q}) C(\bar{q})=1$. Therefore $A_{t} \leq A_{1}(1+\bar{q})^{t-1}$, and, by (6.6) and (6.7), $c_{t} \leq A_{1} L(1+\bar{q})^{t-1}$ for all $t$. The set of programs satisfying the constraints (6.6)-(6.8) for the given $n_{1}, x_{1}, A_{1}$ is therefore compact in the product topology, so, any sequence $\left\{c_{t}^{k}, q_{t}^{k}, A_{t}^{k}\right\}$ of programs satisfying (6.6)-(6.8) has a subsequence that converges to a limit $\left\{c_{t}, q_{t}, A_{t}\right\}$ that also satisfies (6.6)-(6.8).

Since the constraints (6.6)-(6.8) imply $c_{t} \leq A_{1} L(1+\bar{q})^{t-1}$ for all $t$, over the set of programs $\left\{c_{t}, q_{t}, A_{t}\right\}$ satisfying these constraints, the value of the objective function in (6.5) is bounded above by

$$
\sum_{t=1}^{\infty} \beta^{t} \ln (1+\bar{q})^{t} A_{1} L=\sum_{t=1}^{\infty} \beta^{t}\left[t \ln (1+\bar{q})+\ln A_{1} L\right],
$$

which is finite if $A_{1}$ is finite. Since $c_{t}=\min \left(n_{1} x_{1}, A_{1} L\right)$ for all $t$ is an option in problem (6.5), with payoff $\ln \left(\min \left(n_{1} x_{1}, A_{1} L\right)\right) /(1-\beta)>-\infty$, it follows that the supremum of the objective function over the set of programs $\left\{c_{t}, q_{t}, A_{t}\right\}$ satisfying (6.6)-(6.8) is finite. Noting that the initial data $n_{1}$ and $x_{1}$ enter the specification of problem (6.5) only through the product $n_{1} x_{1}$, let $V\left(n_{1} x_{1}, A_{1}\right)$ be the value of this supremum, and let $\left\{c_{t}^{k}, q_{t}^{k}, A_{t}^{k}\right\}$ be a sequence of programs satisfying these constraints such that

$$
\lim _{k \rightarrow \infty} \sum_{t=1}^{\infty} \beta^{t} \ln c_{t}^{k}=V\left(n_{1} x_{1}, A_{1}\right) .
$$

Further, let $\left\{c_{t}, q_{t}, A_{t}\right\}$ be a limit of a convergent subsequence of the sequence $\left\{c_{t}^{k}, q_{t}^{k}, A_{t}^{k}\right\}$. Then, as mentioned above, $\left\{c_{t}, q_{t}, A_{t}\right\}$ satisfies (6.6)-(6.8). Moreover, by continuity of the logarithm,

$$
\sum_{t=1}^{\infty} \beta^{t} \ln c_{t}=\lim _{k \rightarrow \infty} \sum_{t=1}^{\infty} \beta^{t} \ln c_{t}^{k}
$$

i.e., the supremum for problem (6.5) is actually attained by the program $\left\{c_{t}, q_{t}, A_{t}\right\}$ and hence is a maximum.

By Lemma 6 and the principle of dynamic programming, the function $V($.) satisfies the functional equation

$$
V(n x, A) \equiv \max _{c, q}[\beta \ln c+\beta V(A(1+q), A(1+q))],
$$


where $c$ and $q$ must satisfy the constraint

$$
c=\min (n x, A L)-A L(1+q) C(q) .
$$

Moreover the choice of $c$ and $q$ in (6.9) corresponds to the optimal first-period choice in (6.5) when the initial data are $n, x$,and $A$.

We first consider the special case $n_{1} x_{1}=A_{1} L$, where we don't have to bother about the difference between (6.6) and (6.7). To simplify the notation set $V^{*}(A):=$ $V(A, A)$. Then we obtain:

Lemma 8. $V^{*}(A)=\sum_{t=1}^{\infty} \beta^{t} \ln A+V^{*}(1)=\frac{\beta}{1-\beta} \ln A+V^{*}(1)$.

Proof. Let $\left\{c_{t}, q_{t}, A_{t}\right\}$ be an optimal program for problem (6.5) with an initial productivity level $A$ and initial aggregate capacity $n x=A L$. Given that $\left\{c_{t}, q_{t}, A_{t}\right\}$ satisfies the constraints (6.6)-(6.8) for $n x$ and $A$, clearly the program $\left\{c_{t} / A, q_{t}, A_{t} / A\right\}$ satisfies the same constraints for the initial aggregate capacity $\hat{n} \hat{x}=1$ and the initial productivity level $\hat{A}_{1}=1$. Therefore

$$
\begin{aligned}
V^{*}(1) & \geq \sum_{t=1}^{\infty} \beta^{t} \ln \left(c_{t} / A_{1}\right)=\sum_{t=1}^{\infty} \beta^{t}\left[\ln c_{t}-\ln A_{1}\right] \\
& =V^{*}\left(A_{1}\right)-\frac{\beta}{1-\beta} \ln A_{1} .
\end{aligned}
$$

A precisely symmetric argument also shows that

$$
V^{*}\left(A_{1}\right) \geq V^{*}(1)+\frac{\beta}{1-\beta} \ln A_{1},
$$

and the lemma follows.

From (6.9) and (6.10), one now obtains:

$$
V^{*}(A) \equiv \max _{c, q}\left[\beta \ln c+\beta V^{*}(A(1+q))\right]
$$

where $c$ and $q$ must satisfy the constraint

$$
c=A L(1-(1+q) C(q)) .
$$

Upon substituting from Lemma 7 and (6.12) into (6.11), we obtain

$$
V^{*}(A)=\beta \ln A L+\beta \max _{q}\left[\ln (1-(1+q) C(q))+\frac{\beta}{1-\beta}(\ln A+\ln (1+q))\right]+\beta V^{*}(1) .
$$


The choice of $q$ in (6.13) is obviously independent of $A$ and must satisfy the first-order condition

$$
-\frac{(1+q) C^{\prime}(q)+C(q)}{1-(1+q) C(q)}+\frac{\beta}{1-\beta} \frac{1}{(1+q)}=0
$$

which is easily seen to be equivalent to condition (4.5), i.e. $q=q^{* *}$ is the unique solution to the maximization problem in (6.13). By the principle of dynamic programming it follows that the program $\left\{c_{t}, q_{t}, A_{t}\right\}$ such that for $t=1,2, \ldots$,

$$
\begin{aligned}
c_{t} & =A_{t} L\left(1-\left(1+q^{* *}\right) C\left(q^{* *}\right)\right) \\
q_{t} & =q^{* *} \\
A_{t} & =A_{t-1}\left(1+q^{* *}\right)
\end{aligned}
$$

is the unique solution to problem (6.5) for initial conditions satisfying $n_{1} x_{1}=A_{1} L$. For initial conditions with $n_{1} x_{1} \neq A_{1} L$, the principle of dynamic programming in combination with (6.9) and (6.13) implies that the unique solution to problem (6.5) satisfies

$$
\begin{aligned}
\left(c_{1}, q_{2}\right) & =\arg \max \left[\beta \ln c_{1}+\beta V^{*}\left(A_{1}\left(1+q_{2}\right)\right)\right] \\
& =\arg \max \left[\ln c_{1}+\beta \ln A_{1}\left(1+q_{2}\right)+\frac{\beta}{1-\beta}\left(\ln A_{1}\left(1+q_{2}\right)\right)\right]
\end{aligned}
$$

with the constraint (6.10), as before, and, for $t=2,3, \ldots,(6.14)-(6.16)$. This completes the proof of Proposition 6. 


\section{References}

[1] P. Aghion and P. Howitt, Endogenous Growth Theory, Cambridge, MIT Press (1998).

[2] H. Bester and E. Petrakis, Wage and Productivity Growth in a Competitive Industry, Working Paper 98-29, Departamento de Economía, Universidad Carlos III de Madrid, (1998).

[3] D. Cass, Optimum Growth in an Aggregative Model of Capital Accumulation, Review of Economic Studies, 32, (1965), 233-240.

[4] G. Grossman and E. Helpman, Innovation and Growth in the Global Economy, Cambridge, MIT Press (1991).

[5] M. Hellwig, The Conceptual Structure of Macroeconomic Models: The Income Equation, WWZ-Discussion Paper no. 9308, University of Basle (1993).

[6] N. Kaldor, Capital Accumulation and Economic Growth, in: The Theory of Capital, edited by F. Lutz, London: Macmillan (1961).

[7] Ch. Klingen, On the Role of Aggregate Demand Externalities in QualityLadder Models of Endogenous Growth, WWZ-Discussion Paper no. 9311, University of Basle (1993).

[8] T. Koopmanns, On the Concept of Optimal Growth, in: The Econometric Approach to Development Planning, edited by T. Koopmanns, Amsterdam: North Holland (1965).

[9] P. Peretto, Sunk Costs, Market Structure, and Growth, International Economic Review, 37, (1996), 895-923.

[10] R. Radner, Existence of Equilibrium of Plans, Prices, and Price Expectations in a Sequence of Markets, , Econometrica, 40, (1972), 289-303. 
[11] F. Ramsey, A Mathematical Theory of Saving, The Economic Journal, 38, (1928), 543-559.

[12] P. Romer, Endogenous Technological Change, Journal of Political Economy, 98, (1990), S71-S102.

[13] J. Schumpeter, Theorie der wirtschaftlichen Entwicklung, (1911); Theory of Economic Development, Cambridge MA: Harvard University Press (1934).

[14] K. Shell, Inventive Activity, Industrial Organization and Economic Growth, in: Models of Economic Growth, edited by James A. Mirrlees and Nicholas H. Stern. New York: Wiley (1973).

[15] R. Solow, Growth Theory: An Exposition, London (The Radcliffe Lectures), (1970). 